\title{
A model study of the January 2006 low total ozone episode over Western Europe and comparison with ozone sonde data
}

\author{
A. Mangold ${ }^{1}$, J.-U. Grooß ${ }^{2}$, H. De Backer ${ }^{1}$, O. Kirner ${ }^{3}$, R. Ruhnke ${ }^{3}$, and R. Müller ${ }^{2}$ \\ ${ }^{1}$ Royal Meteorological Institute of Belgium, Brussels, Belgium \\ ${ }^{2}$ Research Centre Jülich, Institute for Chemistry and Dynamics of the Geosphere 1: Stratosphere, Jülich, Germany \\ ${ }^{3}$ Research Centre Karlsruhe, Institute for Meteorology and Climate Research, IMK, Karlsruhe, Germany
}

Received: 1 December 2008 - Published in Atmos. Chem. Phys. Discuss.: 5 March 2009

Revised: 15 July 2009 - Accepted: 17 July 2009 - Published: 8 September 2009

\begin{abstract}
Total column and stratospheric ozone levels at mid-latitudes often reveal strong fluctuations on time scales of days caused by dynamic processes. In some cases the total ozone column is distinctly reduced below climatological values. Here, a very low total ozone episode around 19 January 2006 over Western Europe is investigated when the observed total ozone column over Uccle (BE), measured by a Brewer spectrophotometer, reached a daily minimum of $200 \mathrm{DU}$, the lowest recorded value at this station. In order to investigate the mechanisms leading to the ozone minimum, the present study used data from (i) six ozone sounding stations in Western and Middle Europe, (ii) ECMWF meteorological fields, (iii) a simulation of the CLaMS model for January 2006, (iv) a multi-year run of the chemistry transport model KASIMA, and (v) a six-year run of the climate chemistry model ECHAM5/MESSy1. The ozone decrease at different heights was quantified and it was determined to what extent different transport mechanisms, and instantaneous, insitu chemical ozone depletion contributed to the event. All three models reproduced the evolution and formation of the event. The ozone column decrease between $\Theta=300$ and $750 \mathrm{~K}$ was strongest at Uccle (BE) and De Bilt (NL) with 108 and 103 DU, respectively, and somewhat lower at Hohenpeissenberg (DE), Payerne (CH), Prague (CZ) and Lerwick (UK) with 85, 84, 83 and $74 \mathrm{DU}$, respectively. This analysis demonstrated that mainly the displacement of the ozone depleted polar vortex contributed to the ozone column decrease. Advection of ozone-poor low-latitude air masses
\end{abstract}

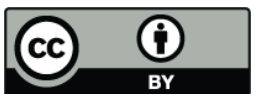

Correspondence to: A. Mangold (alexander.mangold@oma.be) was important in the UTLS region. The vertical displacement of isentropes connected with divergence of air out of the column was found to be of minor importance compared to the horizontal transport processes. Severe low total ozone episodes seem to occur when the mentioned mechanisms are superimposed. Instantaneous, in-situ chemical ozone depletion accounted for only $2 \pm 1 \%$ of the overall total ozone decrease at the sounding stations.

\section{Introduction}

Total ozone columns at mid-latitudes often reveal strong fluctuations on time scales of days caused by atmospheric dynamics. These processes can lead to a rapid, distinct reduction of the total ozone column distinctly below climatological values, and an equally rapid recovery. The relation between these fluctuations and meteorological conditions such as tropospheric high pressure systems has been investigated since decades (e.g., Dobson et al., 1929; Reed, 1950). More recently, very low total ozone column episodes or "ozone mini-holes" became a focus of research (e.g., McKenna et al., 1989; Newman et al., 1988; Peters et al., 1995). Climatologies of such events together with the prevailing meteorological conditions are well documented both for the Northern and Southern Hemisphere (Newman et al., 1988; James, 1998). Mainly dynamic mechanisms have been established to be responsible for their development. These processes are described in detail elsewhere (e.g., Peters et al., 1995; Reid et al., 2000; Teitelbaum et al., 2001; Koch et al., 2005), so only a brief description is given.

Published by Copernicus Publications on behalf of the European Geosciences Union. 
The term ozone mini-hole may lead to confusion with the severe chemical ozone depletion appearing regularly over the polar regions in springtime (Solomon, 1999; WMO, 2006). Whereas these ozone holes are driven by chemistry, in the case of ozone mini-holes dynamics is playing the dominant role. In order to be unambiguous, we will use in the following the term very low total ozone episode or event.

Such events mostly coincide with anticyclonic systems and ridging patterns in the tropopause region caused by poleward Rossby-wave breaking events. These systems are often related to a blocking surface high pressure system. Such pressure systems at higher latitudes will advect climatologically ozone-poor low-latitude air masses on their western flank polewards. Associated with these phenomena is a lifting of the tropopause, leading to a larger column-fraction filled with tropospheric ozone-poor air. The ridging pattern in the tropopause region perturbes the air flow in the lower stratosphere, leading to adiabatic uplift of air parcels. The uplift and resulting air parcel expansion leads to a lower ozone concentration in the air parcel. The total ozone column is decreased if also the pressure difference between isentropes decreases and thus net-divergence of air out of the column compensates for the air parcel expansion. Another mechanism responsible for very low total ozone episodes, in particular in winter and springtime, is the displacement of the stratospheric polar vortex, caused by a sudden stratospheric warming or other distortions. Air masses in the Antarctic polar vortex regularly experienced extreme chemical ozone depletion in recent decades and, similarly, strong chemical ozone destruction occurred in the Arctic in cold winters (e.g., Tilmes et al., 2006; WMO, 2006). Under such conditions, a displacement of the polar vortex will lead to low total ozone columns over regions normally not affected by severe chemical ozone destruction in the stratosphere. These two dynamic processes can be superimposed, leading to severe low total ozone column values (Petzoldt, 1999; James and Peters, 2002). In-situ chemical ozone destruction in the column within the timescale of such very low total ozone episodes is assumed to be negligible (e.g., Hood et al., 2001).

Correlations between very low total ozone events and features of the planetary circulation were studied by several authors. Orsolini and Limpasuvan (2001) investigated 20 years of TOMS (Total Ozone Mapping Spectrometer) measurements with respect to correlations of low-ozone episodes with the North Atlantic Oscillation (NAO). They concluded that such episodes appear more frequently over the EuroAtlantic sector in the high NAO phase, when the prevailing, upper tropospheric westerly jet is displaced poleward and acquires a stronger northward tilt relative to climatology. Hood and Soukharev (2005) investigated long-term trends of winter- and springtime column ozone and attributed the variability they found to changes of the Brewer-Dobson circulation and to planetery wave forcing. Koch et al. (2005) derived from total ozone and ozone profile measurements in Switzerland a climatology of low total ozone events and concluded that long-range transport of climatologically ozone-poor air masses in combination with blocking surface high systems is prevailing and local vertical displacement of isentropes is less important.

Case studies were performed by several authors. Semane et al. (2006) analysed a low total ozone episode over a subtropical site in the austral late autumn, concluding that both planetary wave activity connected with influx of tropical air in the lower stratosphere and shifting of the early polar vortex were responsible. Allen and Nakamura (2002) reconstructed with a tracer transport model the record low total ozone column of 165 DU over Europe on 30 November 1999. Poleward transport of ozone-poor subtropical air, adiabatic uplift of air masses, and displacement of the Arctic vortex could explain the ozone reduction within 10 to $20 \mathrm{DU}$. Orsolini and Nikulin (2006) used meteorological analyses and satellite measurements to investigate a low-ozone episode of 250 DU over the North Sea and Scandinavia during the extreme summer heatwave in August 2003. They concluded that a blocking high system over Europe and a displaced Arctic pool of ozone-poor air in the stratosphere were responsible for that event.

However, studies involving explicit modelling of low total ozone events are rare and chemistry modelling is mostly missing. Orsolini et al. (1995) performed a 7-day simulation with a General Circulation Model (GCM) of a low ozone episode in late January 1992 over Northern Europe. Ozone was treated as a passive tracer. The GCM was able to reproduce that event showing that long-range transport of ozonepoor subtropical air together with the uplift of isentropes and shifting of polar vortex air were responsible. Hood et al. (2001) studied 71 low total ozone events between 1980 and 1993. They used a simple transport model without chemistry and concluded that all extreme ozone minima were consistent with an almost purely dynamic origin. Ozone loss caused by heterogeneous chemistry due to the presence of polar stratospheric clouds (PSC) was estimated to contribute less than $1 \%$ to the observed ozone column reduction.

Here, we contribute to the discussion on the formation mechanisms of low total ozone episodes, investigating in detail the very low total ozone episode around 19 January 2006 over Western Europe with a focus on reproducing this event by modelling both dynamics and chemistry. On that day, the total ozone column over Uccle, Belgium, measured by a Brewer spectrophotometer, reached a daily minimum of $200 \mathrm{DU}$, the lowest value recorded at this site since start of the time series in 1971 (the mean for January is 330 DU). Similar, or even lower values were measured at other sites in Western Europe. Keil et al. (2007) reported for the 19 January 2006 for Reading in the UK a daily minimum ozone column value of $177 \mathrm{DU}$. They analysed the episode by ozone profile measurements at two ozone sounding stations and back trajectory calculations ending in Reading. They concluded that about two-third of the column reduction over the UK originated from UTLS dynamics and the other third 
Table 1. Overview of the ozone sounding stations from which data were taken.

\begin{tabular}{lll}
\hline Station/Country & Latitude/Longitude & available days in January \\
\hline Lerwick, UK & $60.1^{\circ} \mathrm{N}, 1.2^{\circ} \mathrm{W}$ & $4,11,18,25$ \\
De Bilt, NL & $52.1^{\circ} \mathrm{N}, 5.2^{\circ} \mathrm{E}$ & $5,12,19$ \\
Uccle, BE & $51.0^{\circ} \mathrm{N}, 4.3^{\circ} \mathrm{E}$ & $4,6,9,11,13,16,18,19,20,23,25$ \\
Prague, CZ & $50.0^{\circ} \mathrm{N}, 14.5^{\circ} \mathrm{E}$ & $2,4,6,11,13,16,18,20,23,25$ \\
Hohenpeissenberg, DE & $47.8^{\circ} \mathrm{N}, 11.0^{\circ} \mathrm{E}$ & $2,4,9,11,13,16,20,25$ \\
Payerne, $\mathrm{CH}$ & $46.8^{\circ} \mathrm{N}, 6.9^{\circ} \mathrm{E}$ & $2,4,6,9,11,13,14,16,18,20,23,25,26$ \\
\hline
\end{tabular}

from the mid-stratospheric displacement of the ozone-poor Arctic vortex. We expand in our work the analysis of Keil et al. (2007) by investigating the causes of the observed total ozone decrease over a broader region of Europe and by including modelling studies which allow not only for conclusions on the dynamics but also on a potential impact of instantaneous, in-situ chemical ozone destruction.

In this work data sets were used from (i) six ozone sounding stations spread over Western and Middle Europe, (ii) ECMWF (European Centre for Medium-Range Weather Forecasts) meteorological fields, (iii) a special simulation of the Chemical Lagrangian Model of the Stratosphere (CLaMS) for January 2006, (iv) a multi-year run of the threedimensional chemistry transport model (CTM) KArlsruhe SImulation model of the Middle Atmosphere (KASIMA), and (v) a six-year run of the climate chemistry model (CCM) ECHAM5/MESSy1 (hereafter referred to as E5/M1).

In the following section we describe the data and models that were used. Thereafter the extreme low total ozone event is illustrated with observations at the ozone sounding stations. Section 4 shows fields of potential vorticity around the time period of the event on the Northern Hemisphere. The model simulations of the ozone column, ozone concentration at different altitudes, chemical species, and chemical ozone change are shown in Sect. 5 and compared to respective measurements at the stations. In Sect. 6, the ozone column decrease at different altitude levels is determined, and, moreover, it is quantified to which extent the different mechanisms were responsible for the low total ozone column. The discussion and conclusions close the paper.

\section{Instruments, data and modelling}

\subsection{Ozone sonde data}

Ozone profile measurements from six ozone sounding stations have been used in this study. The exact geographical coordinates are given in Table 1 . The most northwesterly station is Lerwick (UK) on the Shetland Islands. Uccle (BE) and De Bilt (NL) represent Western European locations whereas Payerne $(\mathrm{CH})$, Hohenpeissenberg (DE) and Prague (CZ) represent the gradual transition to middle and eastern
European locations. The ozone sondes used at the stations are of the ECC-type (electrochemical concentration cell), except for Hohenpeissenberg where a Brewer-Mast (BM) sensor is in operation. The launch time of the individual sondes is fixed to $11: 30 \mathrm{UT} \pm 15 \mathrm{~min}$, except for Hohenpeissenberg where the launch time is around 05:30 UT. Profiles of temperature and pressure are simultaneously measured. The vertical resolution is in the order of $100 \mathrm{~m}$. At all stations there are data for several days in January, including the 18th, 19th or 20th, but only at De Bilt and Uccle there were soundings on the 19th, and only at Uccle on all three consecutive days.

The accuracy of ozone soundings has been discussed in reports of different intercomparison campaigns. The report of the Balloon Ozone Intercomparison Campaign (Hilsenrath et al., 1986) mentions that the deviation of the different ozone sondes (BM and ECC types) from a reference UV absorption instrument is in the range of 5 to $10 \%$. The total error for ECC sondes can be estimated to be within $-7 \%$ to $+17 \%$ in the upper troposphere, $\pm 5 \%$ in the lower stratosphere up to $10 \mathrm{hPa}$ and $-14 \%$ to $+6 \%$ at $4 \mathrm{hPa}$ (Komhyr et al., 1995). More recently, Smit et al. (2007) showed in intercomparison chamber experiments with ECC sondes that standardisation of operating procedures (in particular the cathode sensing solution) can yield a precision better than $\pm(3$ to 5$) \%$ and an accuracy of about \pm (5 to 10$) \%$ up to $30 \mathrm{~km}$ altitude.

At Uccle, ozone soundings are launched since 1969 three times a week. However, only ozone data from 1995 to 2006 were used to calculate a mean January ozone profile serving as a reference profile. This time limitation was imposed to exclude effects of the Pinatubo volcano eruption in 1991 on the stratospheric ozone layer. The Uccle time series have been homogenised (Lemoine and De Backer, 2001) to account for changes in the ozone sonde type. Total ozone is also measured routinely at Uccle with a Dobson and two Brewer spectrophotometers. The error on the ozone column measurements with a well maintained and calibrated Dobson instrument may be estimated to 2 to $3 \%$ (Basher, 1982). The Brewer instruments have a similar accuracy and optimal calibrated instruments can reach uncertainties of $0.6 \%$ for daily values (Fioletov et al., 2005). 
Table 2. Overview of model resolution.

\begin{tabular}{lll}
\hline Model & horizontal resolution & vertical resolution \\
\hline CLaMS & $100 \mathrm{~km}\left(30^{\circ}\right.$ to $\left.90^{\circ} \mathrm{N}\right)$ & 32 levels (between $\Theta=350$ and $700 \mathrm{~K})$ \\
& $400 \mathrm{~km}\left(0^{\circ}\right.$ to $\left.30^{\circ} \mathrm{N}\right)$ & \\
KASIMA & $\mathrm{T} 21\left(5.68^{\circ} \times 5.68^{\circ}\right)$ & 63 levels $(\approx 7$ to $120 \mathrm{~km})$ \\
E5/M1 & $\mathrm{T} 42\left(2.80^{\circ} \times 2.80^{\circ}\right)$ & 39 levels $($ surface to $\approx 80 \mathrm{~km})$ \\
\hline
\end{tabular}

\subsection{Meteorological data}

Meteorological fields of the horizontal and vertical winds, temperature, specific humidity, and pressure were retrieved from analyses belonging to the operational ECMWF IFS model in January 2006 (T511L60, i.e. 60 height levels from surface pressure to $0.1 \mathrm{hPa}$, spatial resolution corresponding to a $0.5^{\circ} \times 0.5^{\circ}$ grid). Our retrieval for the CLaMS model requested the meteorological fields interpolated on a $1^{\circ} \times 1^{\circ}$ grid (i.e. linear interpolation after spectral truncation), for the 60 height levels at 06:00, 12:00, 18:00 UT, and for whole January 2006.

\subsection{Description of models}

For this study, simulations of two chemical transport models and one chemistry climate model are used. In Table 2, an overview of the models' spatial resolution is given.

For this study the three-dimensional CTM CLaMS (Chemical Lagrangian Model of the Stratosphere), which simulates the dynamics and chemistry of the atmosphere along trajectories of multiple air parcels (McKenna et al., 2002a,b), was run for whole January 2006. The vertical coordinate is potential temperature with 32 levels between $\Theta=350$ and $700 \mathrm{~K}$, corresponding to an average vertical resolution of $\Theta=11 \mathrm{~K}$ (or about $500 \mathrm{~m}$ ). Mixing is simulated at those locations where strong wind shear occurs using a Lagrangian mixing algorithm (Konopka et al., 2004, 2005). Meteorological fields were taken from 6-hourly operational ECMWF analyses. Ozone was treated as passive tracer and was initialised with version 1.5 data measured by the Microwave Limb Sounder on the EOS-AURA satellite. Similar to the method described in Grooß and Müller (2007), MLS ozone data between 1 and 4 January 2006 were mapped to the synoptic time 1 January 2006, 12:00 UT, onto a regular $2^{\circ}$ latitude $\times 6^{\circ}$ longitude grid using the CLaMS trajectory module.

The three-dimensional CTM KASIMA (KArlsruhe SImulation model of the Middle Atmosphere) is a global circulation model including stratospheric chemistry for the simulation of the behaviour of physical and chemical processes in the middle atmosphere (Reddmann et al., 2001; Ruhnke et al., 1999). Data from of a multi-year run (1972-2006) were used in this study. The vertical coordinate is pressure. Pressure altitude is calculated as $z=-H \ln \left(p / p_{0}\right)$ where $H=7 \mathrm{~km}$ is a constant atmospheric scale height, $p$ is the pressure, and $p_{0}=1013.25 \mathrm{hPa}$ is a constant reference pressure. The vertical resolution is $0.75 \mathrm{~km}$ between 7 and $22 \mathrm{~km}$, with an exponential increase above. For the meteorology module of KASIMA, the nudged model version has been used (Kouker et al., 1999). In this version, the model is nudged towards the operational ECMWF analyses of temperature, vorticity and divergence. The model run was initialized for 1 April 1972, with adjusted 2-D-model data of the Max Planck Institute (MPI) for Chemistry in Mainz (Gidel et al., 1983; Grooß, 1996). Tropospheric trends of source gases as $\mathrm{N}_{2} \mathrm{O}, \mathrm{CH}_{4}$, and $\mathrm{CFCs}$ have been prescribed during the model run according the IPCC/WMO baseline scenario $\mathrm{Ab}$ (WMO, 2003). The photolysis rates were calculated online in KASIMA by using the Fast-J2 model of Bian and Prather (2002).

The ECHAM/MESSy (E5/M1) atmospheric chemistry model is a numerical chemistry and climate simulation system that includes sub-models describing troposphere and middle atmosphere processes and their interaction with oceans, land and human influences (see Jöckel et al., 2006, and references therein). It uses the first version of the Modular Earth Submodel System (MESSy1; Jöckel et al., 2005) to link multi-institutional computer codes. The core atmospheric model is the fifth generation European Centre Hamburg general circulation model (ECHAM5; Röckner et al., 2006). E5/M1 was used to perform a six-year simulation (2000-2006). Temperature, vorticity, divergence and ground pressure were nudged towards ECMWF operational analysis data up to $10 \mathrm{hPa}$. The chemical initialisation was done with data of the S1-simulation of the MPI for Chemistry in Mainz, Germany (T42L90, 1 January 1998-31 December 2005; Jöckel et al., 2006). The most important submodels used in this simulation are: OFFLEM, ONLEM, and TNUDGE (prescribed, calculated, pseudo-emissions, respectively, of chemical species, Kerkweg et al., 2006), MECCA (gas-phase chemistry, Sander et al., 2005), CLOUD (cloud cover and microphysics, Tost et al., 2007a), LNOX (lightning $\mathrm{NO}_{\mathrm{x}}$, Tost et al., 2007b), PSC (processes related to PSCs, Buchholz, 2005). 


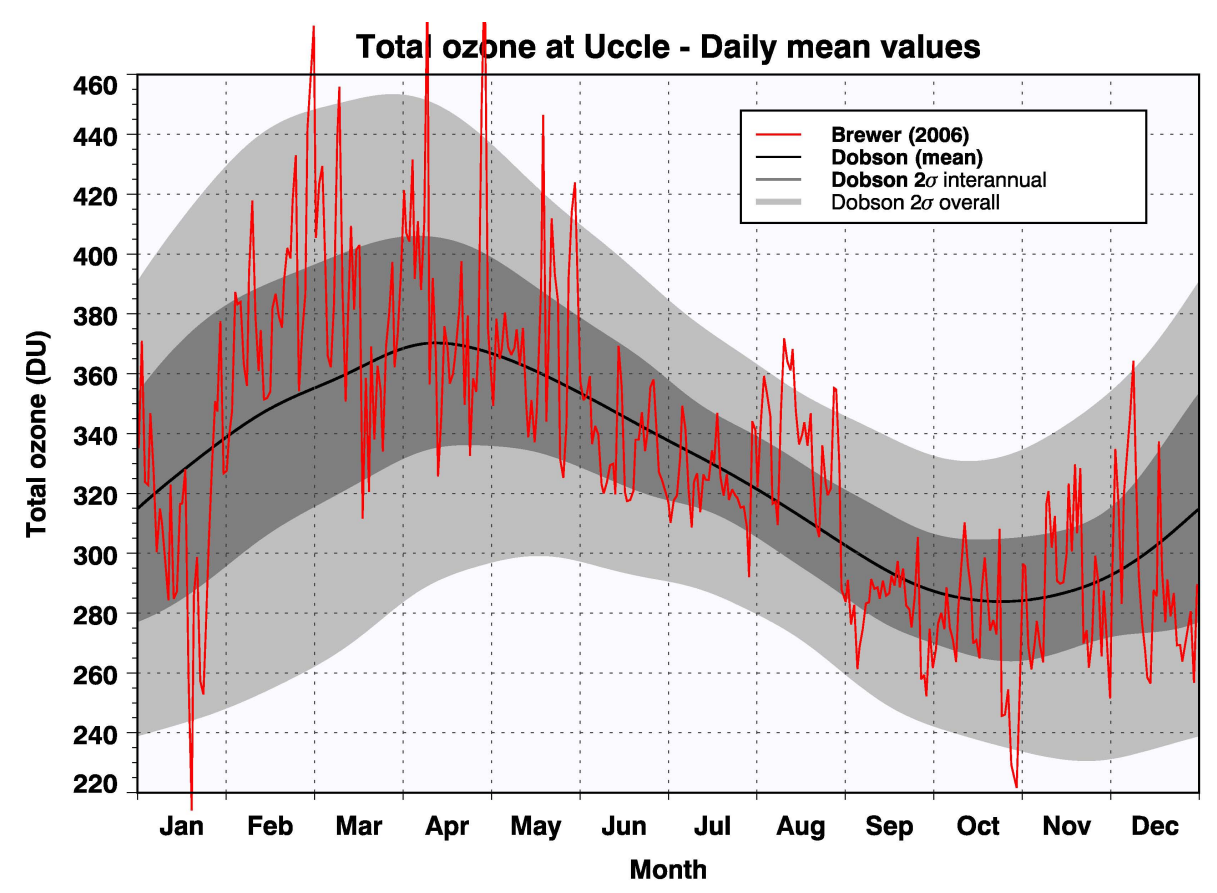

Fig. 1. Total ozone column measured at Uccle; the black line is the mean of all Dobson measurements since 1971, the light and dark greyshaded area represent the $95 \%$-percentile-bound (or $2 \sigma$ error) of the overall and the interannual Dobson time-series variability, respectively (see also text). The daily averages of 2006 measured by Brewer No. 16 are given in red.

\section{Observation of the low ozone event}

The very low total ozone episode around 19 January 2006 over Western Europe was detected by both ground-based and profile measurements. Figure 1 shows the evolution of the total ozone column measured at Uccle. The long-time mean (since 1971) of the Dobson measurements and the respective overall and interannual variability are given and the daily total ozone column averages of 2006 measured by Brewer No. 16 are superimposed. The overall variability considers all values of all years of the populations to calculate a running mean of day $X \pm 15$ days, whereas for the interannual variability only the running means of day $X \pm 15$ days of each year are considered. Thus, the record low of 200 DU on 19 January was distinctly outside the $95 \%$-percentile-bounds of both the day-to-day variability and the variation of the total ozone column on a longer perspective. It corresponded to $130 \mathrm{DU}$ less than the long-time mean for 19 January.

Measured ozone profiles over Uccle (BE) and Payerne $(\mathrm{CH})$ are presented in Figs. 2 and 3, respectively. For Uccle, the measured profiles for 16, 18, 19, 20, and 23 January 2006 together with the long-time mean (1995 to 2006) for January are shown. The distinct reduction of ozone in the mid-stratosphere on 18 and 19 January compared to the longtime January mean and to 16 January can clearly be seen. On 19 January, ozone mixing ratios between 3.0 and $4.2 \mathrm{ppmv}$ were observed in the mid-stratosphere between $\Theta=500$ and $700 \mathrm{~K}$, which was up to $1.8 \mathrm{ppmv}$ below the long-time mean and even up to 2.3 ppmv less than measured on 16 January. Also on 20 January, less ozone was observed in the midstratosphere, but, as can be seen in the inserted zoom-image, not in the tropopause region. On 18 January and 19 January, the tropopause over Uccle was distinctly lifted to 13.1 and $12.4 \mathrm{~km}$, respectively, whereas the January mean is $10.8 \mathrm{~km}$. Compared to 16 January, the tropopause was lifted 2.1 and $1.4 \mathrm{~km}$, respectively.

The ozone profiles for Payerne for the same period (Fig. 3) reveal that the situation over Uccle is not a spatially isolated feature. For comparison, the long-time January mean data for Uccle is plotted. Distinctly lower ozone values on $20 \mathrm{Jan}-$ uary compared to 16 January and to the Uccle mean are visible, both in the UTLS region and the mid-stratosphere. On 20 January, ozone mixing ratios between $\Theta=500$ and $700 \mathrm{~K}$ were between 3.4 and 4.5 ppmv, up to $2.7 \mathrm{ppmv}(\Theta=700 \mathrm{~K})$ less than measured on 16 January and up to 1.9 ppmv below the long-time mean at Uccle. Also at Payerne, the tropopause was higher on 18 January $(12.8 \mathrm{~km})$ than on the day of $\min$ imum total ozone (20 January; $12.2 \mathrm{~km}$ ). Compared to 16 January, the tropopause was lifted by 2.1 and $1.5 \mathrm{~km}$ on 18 and 20 January, respectively, in good agreement with the Uccle values.

In Fig. 4 it can be seen that during the low total ozone episode isentropes were uplifted. The uplift and resulting air parcel expansion led to lower ozone concentrations in the air parcel. The total ozone column would decrease if also the pressure difference between two isentropes were to decrease 


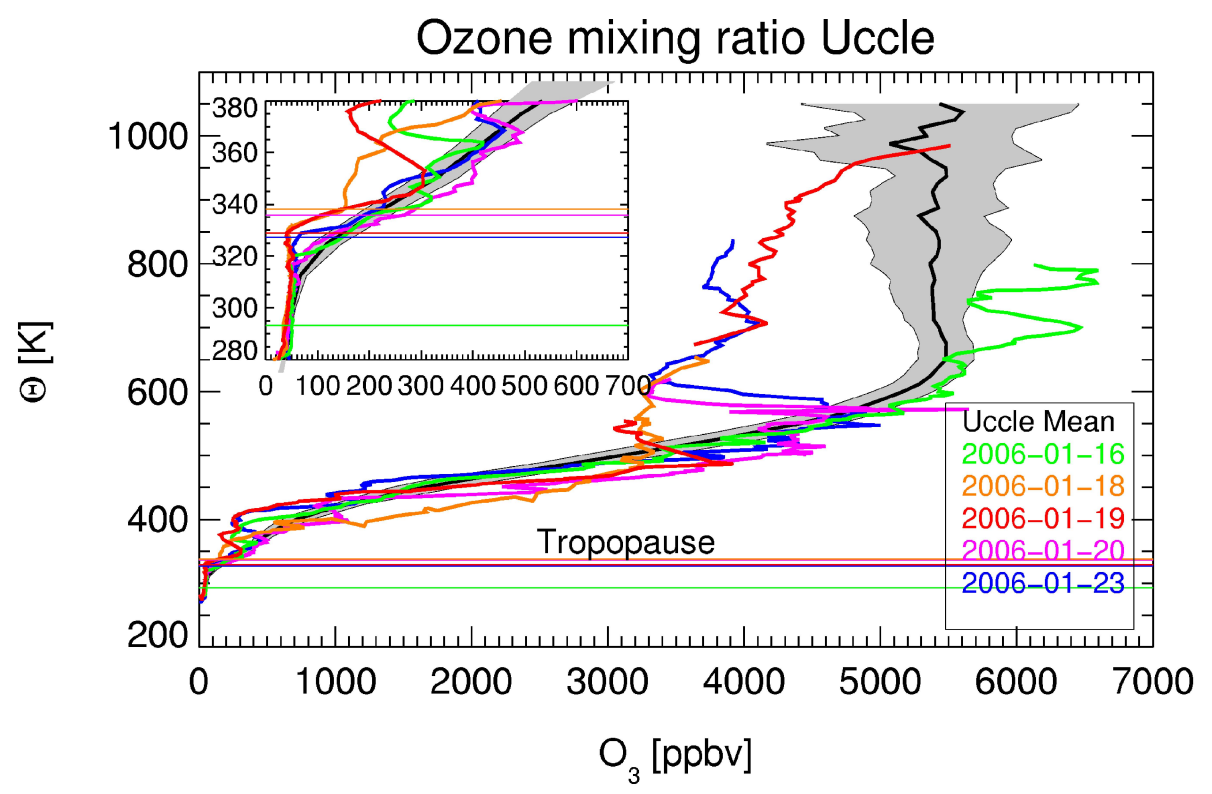

Fig. 2. Measured ozone profiles above Uccle in January 2006; the black line represents the mean of all Uccle soundings in January from 1995 to 2006 and the shaded area the $1 \sigma$ standard deviation. Tropopauses were calculated following WMO criteria. The inserted image shows a zoom into the UTLS region, with ozone in ppbv against $\Theta(\mathrm{K})$.

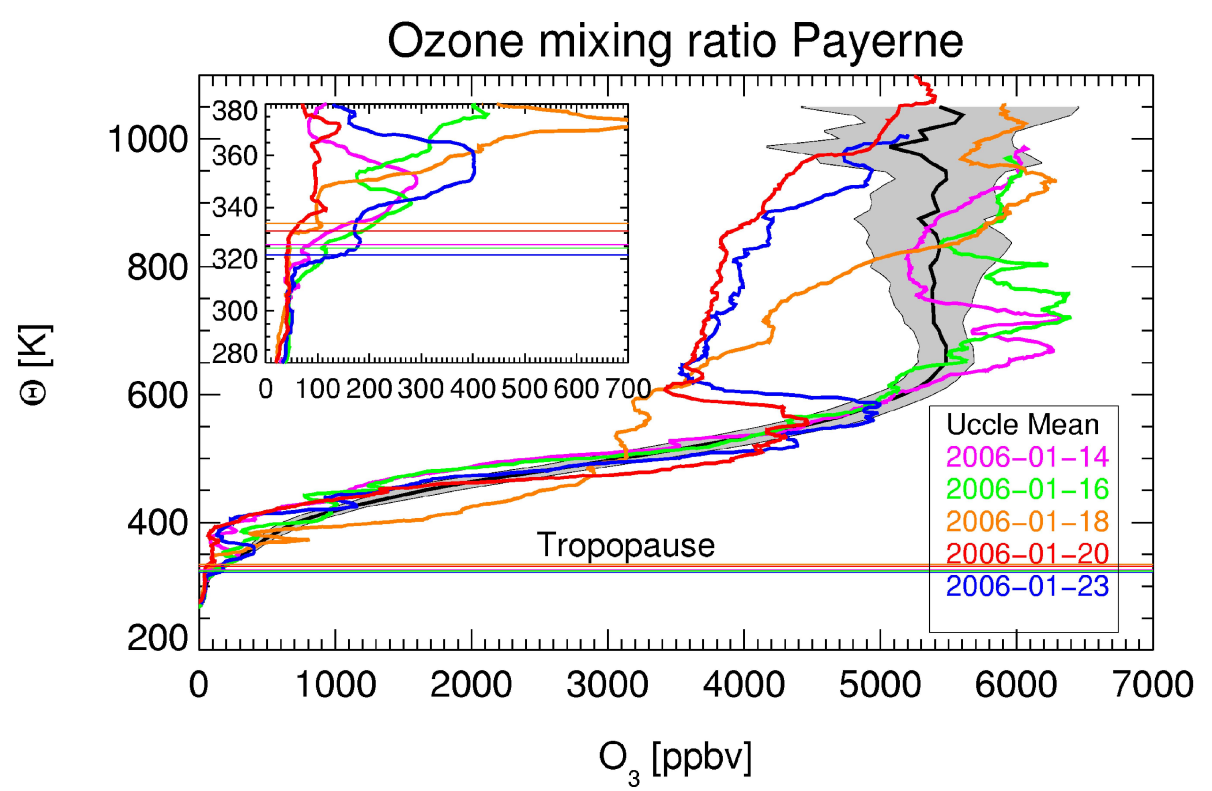

Fig. 3. Measured ozone profiles above Payerne in January 2006; the black line represents the mean of all Uccle soundings in January from 1995 to 2006 and the shaded area the $1 \sigma$ standard deviation. Tropopauses were calculated following WMO criteria. The inserted image shows a zoom into the UTLS region, with ozone in ppbv against $\Theta(\mathrm{K})$. 

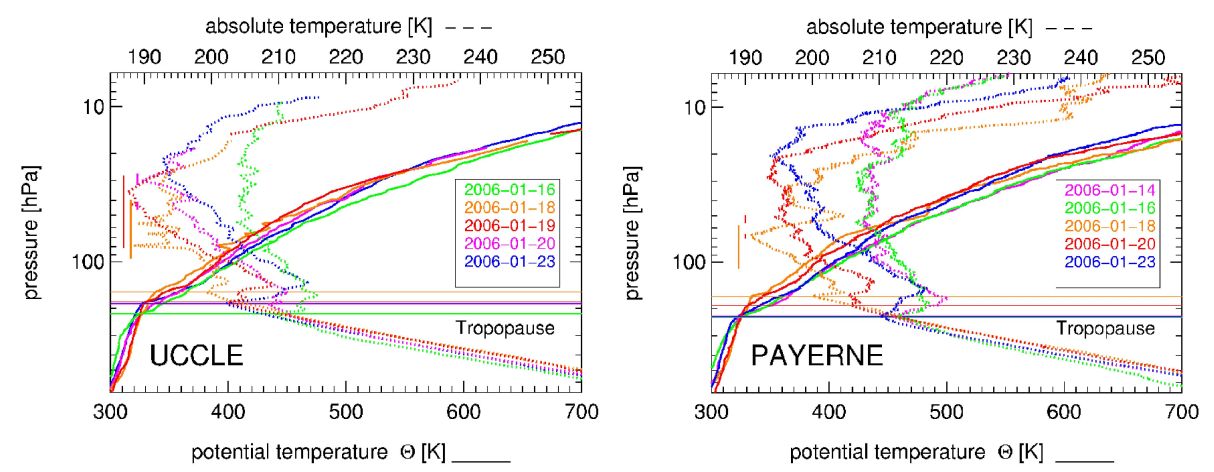

Fig. 4. Height profiles for Uccle (left panel) and Payerne (right panel) of potential temperature (lower $x$-axes, solid lines) and absolute temperature (upper $x$-axes, dotted lines), for same days as in Figs. 2 and 3; tropopauses were calculated following WMO criteria; vertical lines mark altitudes where the threshold for existence of PSCs of nitric acid trihydrate was reached.

so that net-divergence of air out of the column compensated for the air parcel expansion. Marking the uplift, pressure on individual $\Theta$-levels between 330 and $600 \mathrm{~K}$ above Uccle was on average $18 \mathrm{hPa}(\max =33 \mathrm{hPa}, \min =7 \mathrm{hPa})$ less when comparing 19 to 16 January. At Payerne, pressure on individual $\Theta$-levels between 330 and $600 \mathrm{~K}$ was on average $16 \mathrm{hPa}(\max =33 \mathrm{hPa}, \min =4 \mathrm{hPa})$ less when comparing 20 to 16 January. Marking the net-divergence, the average pressure difference between isentropes (from $\Theta=330$ to $600 \mathrm{~K}$, in $30 \mathrm{~K}$ intervals) decreased on average by $3.6 \mathrm{hPa}(2.3 \mathrm{hPa})$ between 16 and 19 (16 and 20) January over Uccle (Payerne). At the other sounding stations similar observations were made.

The evolution with time of the measured temperature height profiles (Fig. 4) illustrates very low temperatures in the stratosphere during the low total ozone episode. Over Uccle, minimum temperatures around $190 \mathrm{~K}$ (between 80 and $60 \mathrm{hPa}$ ) were detected on 18 January, around $188 \mathrm{~K}$ $(35 \mathrm{hPa})$ on 19 January, and around $190 \mathrm{~K}(30 \mathrm{hPa})$ on $20 \mathrm{Jan}-$ uary. Over Payerne, minimum temperatures around $193 \mathrm{~K}$ (at $30 \mathrm{hPa}$ ) were detected on 20 January. In Fig. 4, the heights where temperatures were below the threshold for the existence of PSCs consisting of nitric acid trihydrate (following Hanson and Mauersberger, 1988, assuming $10 \mathrm{ppbv} \mathrm{HNO}_{3}$, 5 ppmv $\mathrm{H}_{2} \mathrm{O}$ ) are marked by vertical coloured lines, indicating the potential for heterogeneous chemistry on polar stratospheric cloud particles and chemical ozone loss between 18 to 20 January at altitudes between 100 and $30 \mathrm{hPa}$.

In Table 3, the most important measured parameters describing the very low total ozone episode are summarised. The event was seen on 18 January in the western parts of Europe (Lerwick) and two days later in the middle and eastern parts (Hohenpeissenberg, Payerne and Prague on 20 January 2006). Total ozone column values decreased to 206 DU (De Bilt) and 205 or $200 \mathrm{DU}$ (Uccle, ozone sonde and Brewer spectrophotometer measurements, respectively). Keil et al. (2007) reported for that episode a daily minimum value of total ozone of 177 DU on 19 January 2006, measured with a Dobson spectrophotometer at Reading (UK, $51.5^{\circ} \mathrm{N}$, $\left.1.0^{\circ} \mathrm{W}\right)$. They state that this value is $100 \mathrm{DU}$ below the $3-$ year average daily minimum for Reading. In addition, Table 3 indicates that the tropopause was particularly high at the respective day of minimum total ozone at all of the six investigated stations and that minimum temperatures in the midstratosphere of below $190 \mathrm{~K}$ were detected over Lerwick, De Bilt and Uccle indicating the possibility of polar stratospheric cloud formation.

\section{Potential vorticity fields}

The potential vorticity fields were calculated from ECMWF analysis data. In Figs. 5 and 6, isentropic maps of Ertel's potential vorticity (PV) at $\Theta=325 \mathrm{~K}$ and $500 \mathrm{~K}$, respectively, are shown from 16 to 21 January 2006 for the Northern Hemisphere.

Generally, the $\Theta=325 \mathrm{~K}$ isentrope can be considered to describe the tropopause region with $\mathrm{PV}<2$ characterising tropospheric and $\mathrm{PV}>2$ stratospheric air masses, respectively (Holton, 2004). If the $\Theta=325 \mathrm{~K}$ isentrope shows no longer stratospheric PV values, this indicates lifting of the tropopause and connected uplift of air masses. In Fig. 5 it can be seen that low-latitude air masses of $\mathrm{PV}<2$ were advected and moved eastwards, stretching over the British Isles, Western Europe, and Middle Europe on 18, 19, and 20 January, subsequently. With respect to the vertical extent, from Fig. 4 it is obvious that the uplift of isentropes extended up to $20 \mathrm{hPa}$. Such phenomena are often related to large surface high pressure systems. A respective meteorological analysis of the period revealed that indeed during the event such systems were present over the Atlantic and northern Siberia (not shown).

The potential vorticity fields at $\Theta=500 \mathrm{~K}$ (Fig. 6) indicate that when the low total ozone episode was observed, parts of the polar vortex moved over Western and Middle Europe. On 16 January, the vortex stretched from the North Atlantic 

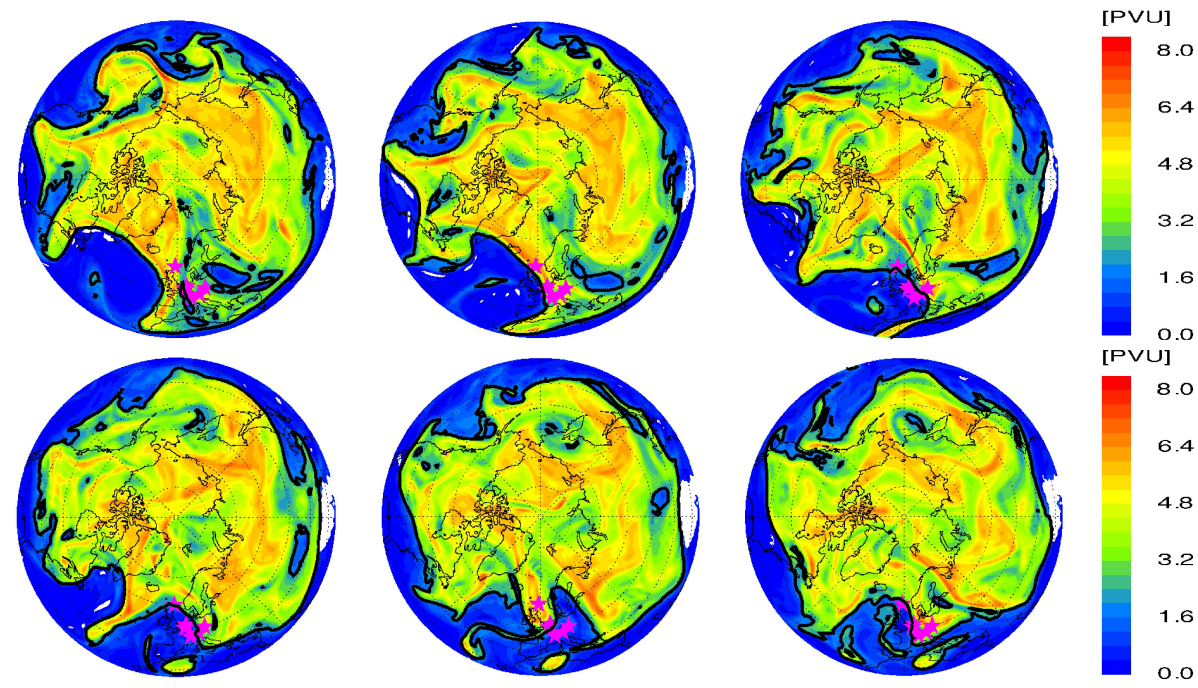

Fig. 5. Ertel's potential vorticity $\left(\mathrm{PV} ; \times 10^{-6} \mathrm{~K} \mathrm{~m}^{2} / \mathrm{kg} \mathrm{s}\right.$ ) at $\Theta=325 \mathrm{~K}$ from 16 to 18 (top row) and 19 to 21 (bottom row) January 2006 , from operational analyses of ECMWF for 12:00 UT; The six ozone sounding stations are marked by pink stars and the PVU=2 level by the thick black contour line.
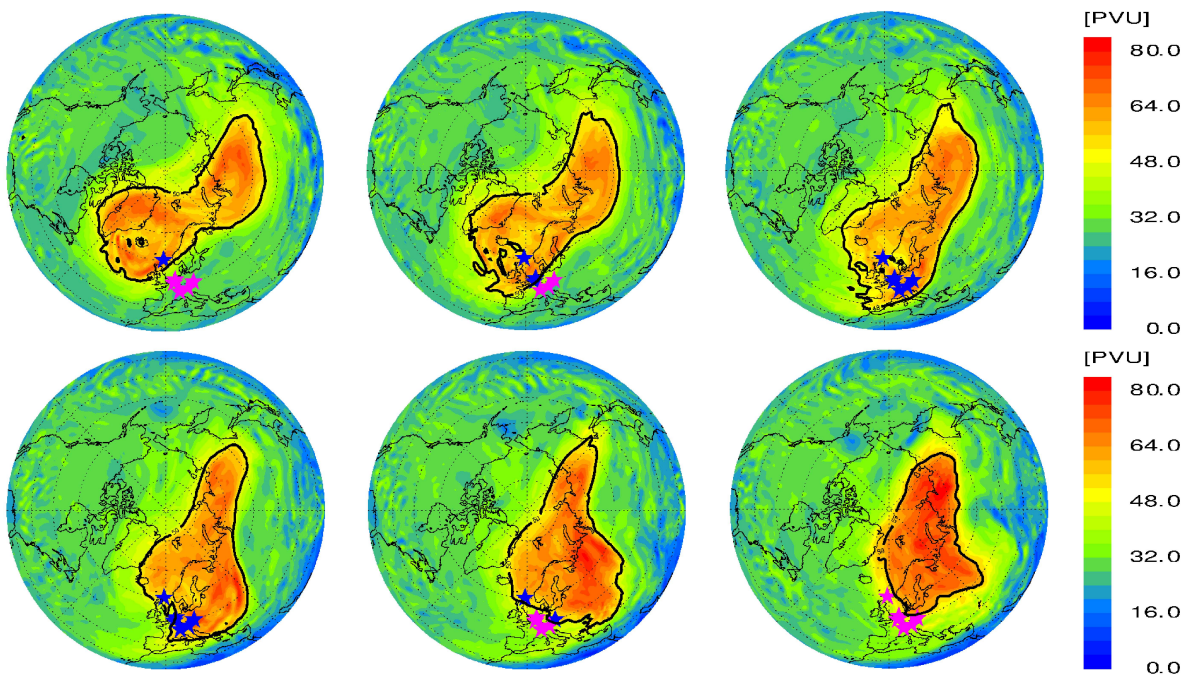

Fig. 6. Ertel's potential vorticity $\left(\mathrm{PV} ; \times 10^{-6} \mathrm{~K} \mathrm{~m}^{2} / \mathrm{kg} \mathrm{s}\right.$ ) at $\Theta=500 \mathrm{~K}$ from 16 to 18 (top row) and 19 to 21 (bottom row) January 2006 , from operational analyses of ECMWF for 12:00 UT; the boundary of the polar vortex (largest gradient of PV) is indicated by the thick black line; the six ozone sounding stations are marked by pink (outside vortex) and blue (inside vortex) stars. 
Table 3. Measured parameters, describing the very low total ozone episode around 19 January 2006. Stations are listed according to the day of minimum total ozone.

\begin{tabular}{lccccc}
\hline Station (day) & \multicolumn{3}{c}{ Ozone Column DU } & $\begin{array}{c}\text { Tropopause Height } \\
\text { hPa/ } \Theta=K / k m\end{array}$ & $\begin{array}{c}\text { Min-Temperature } \\
\text { K }(\mathrm{hPa} / \mathrm{km})\end{array}$ \\
\hline Normal $^{\mathrm{a}}$ & Sonde & Ground $^{\mathrm{b}}$ & & & \\
\hline Lerwick (18) & 303 & 223 & $247^{\mathrm{D}}$ & $175 / 337 / 12.3$ & $188.2(23.5 / 23.8)$ \\
De Bilt (19) & 327 & 206 & $215^{\mathrm{B}}$ & $181 / 330 / 12.4$ & $187.3(39.2 / 21.2)$ \\
Uccle (19) & 317 & 205 & $200^{\mathrm{B}}$ & $183 / 329 / 12.4$ & $187.6(35.4 / 21.9)$ \\
Hohpberg (20) & 318 & 237 & $233^{\mathrm{D}}$ & $164 / 340 / 13.0$ & $192.9(35.1 / 22.0)$ \\
Payerne (20) & 320 & 227 & & $190 / 331 / 12.2$ & $193.2(28.5 / 23.3)$ \\
Prague (20) & 317 & 250 & & $198 / 326 / 11.8$ & $195.2(27.9 / 23.3)$ \\
\hline
\end{tabular}

a calculated from the days when ozone soundings took place in January 2006 before the event.

$\mathrm{b}$ if available; $\mathrm{D}=$ Dobson, $\mathrm{B}=$ Brewer

and Greenland over northern Scandinavia towards Siberia. From the six stations only Lerwick was located below the vortex, however, more below the vortex edge. On the following days parts of the polar vortex moved gradually over Western, Middle, and Eastern Europe. On 18 and 19 January, the vortex was located over all six stations. From the measured ozone profiles over Uccle and Payerne in Figs. 2 and 3 it can be seen that when the polar vortex moved over these locations the ozone levels in the mid-stratosphere were distinctly lower than before the episode or than the long-time mean. At Payerne, where on 20 January the vortex was not situated directly above the station at the $\Theta=500 \mathrm{~K}$-level, the vortex was still well located over the station at higher altitudes (not shown). The displacement of the polar vortex out of its normal near-zonally symmetric form was caused by a minor stratospheric warming in mid-January 2006 (Keil et al., 2007; WMO, 2006).

The described evolution of the potential vorticity fields and the location of the polar vortex showed that both advection of low-latitude air masses, connected with adiabatic uplift, and a displacement of the polar vortex had an influence on the January 2006 low total ozone event. That both the advected low-latitude air masses and the air masses within the polar vortex were ozone-poor will be shown in the following section.

\section{Simulation of the low total ozone episode and compar- ison with observations}

\subsection{Total ozone column}

The measured and simulated total ozone columns between 16 and 21 January 2006 are illustrated in Figs. 7-9 for the models CLaMS, KASIMA, and E5/M1, respectively. KASIMA and E5/M1 simulated the total column, whereas CLaMS simulated the partial column between $\Theta=350$ and $700 \mathrm{~K}$. In the ozone column maps the six ozone sounding stations are marked and whenever a measurement is available, the station is marked by a red circle filled with the respective colour code for Dobson Units. On days when no ozone soundings were made, Dobson measurements were available at De Bilt, Hohenpeissenberg, Lerwick, and Uccle. In addition, Table 4 lists the measured and simulated total and partial ozone columns on the days when minimum total ozone was observed at the six ground stations.

The CLaMS partial ozone column maps (Fig. 7) nicely demonstrate that CLaMS reproduced well the evolution of the low total ozone event, although the model vertical boundaries do not cover the total atmospheric column. Comparing measured (within the same $\Theta$-boundaries as CLaMS) and modelled values, it can be seen that CLaMS agrees very well with the sondes' measurements, in particular on 18 January when CLaMS captured both the core and the edge of the low total ozone region. The zone of low total ozone stretched in particular on 18 and 19 January like a tongue from the Azores towards the northern Atlantic and Western Europe. The patterns of lower and higher ozone values agree very well with the patterns for potential vorticity on $\Theta=325 \mathrm{~K}$ for the same period (see Fig. 5). This indicates that the process of advection of air masses originating in lower latitudes together with uplift of isentropes has an important influence on the total ozone column values.

KASIMA also reproduced well the overall evolution of the low total ozone episode (Fig. 8), especially on 19 and 20 January. Likely caused by its coarser spatial resolution, KASIMA did not capture some finer structures (e.g. on 16 January at Hohenpeissenberg and Prague; 18 January at Prague; 20 January at Uccle; 21 January at Hohenpeissenberg). Again, the patterns of lower and higher ozone values agreed very well with the patterns for potential vorticity on $\Theta=325 \mathrm{~K}$ for the same period (see Fig. 5).

The CCM E5/M1 mainly overestimated the total ozone column during the episode and the core of the low total ozone episode on 17 and 18 January was located too far to the west. However, E5/M1 captured some features, e.g., at Prague on 16 January, at Uccle on 18 January, and at Lerwick on 21 January (Fig. 9). 

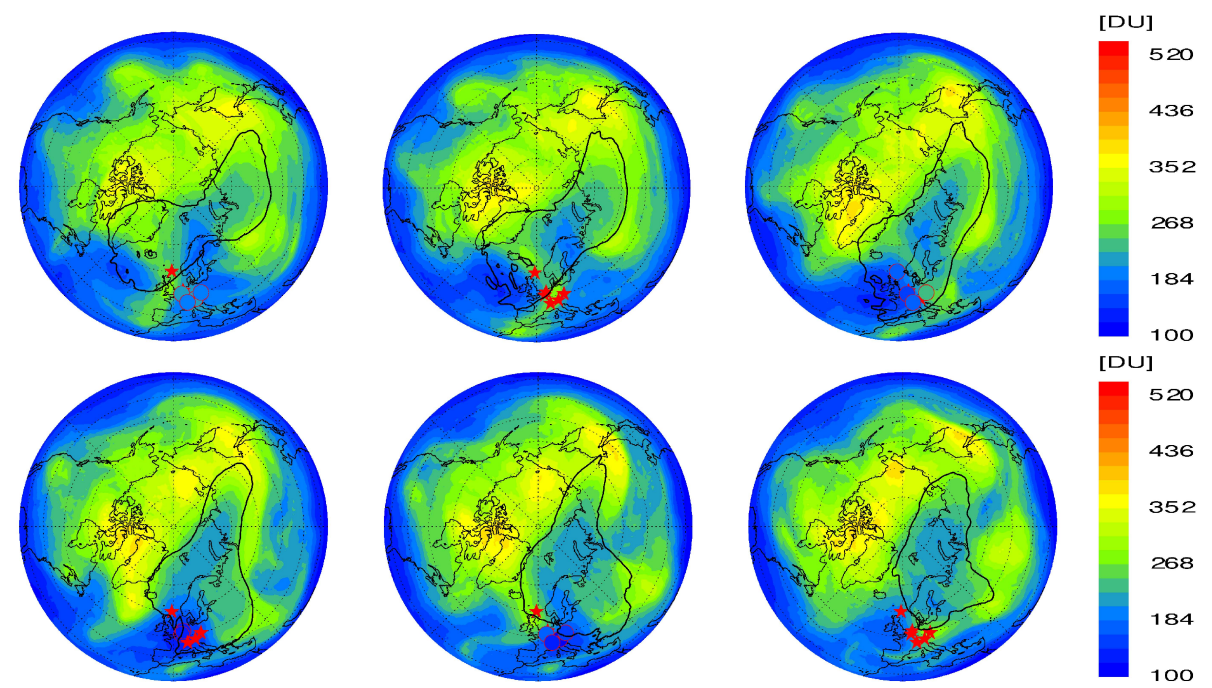

Fig. 7. Partial ozone column $(\Theta=350$ to $700 \mathrm{~K})$ in DU for 16 to 18 (top row) and 19 to 21 (bottom row) January 2006, 12:00 UT, simulated by CLaMS; boundary of the polar vortex is marked by the thick black line; sounding stations are marked either by red stars (no measurement) or by red circles (partial column measurement available, circles filled in respective colour code for Dobson Units).
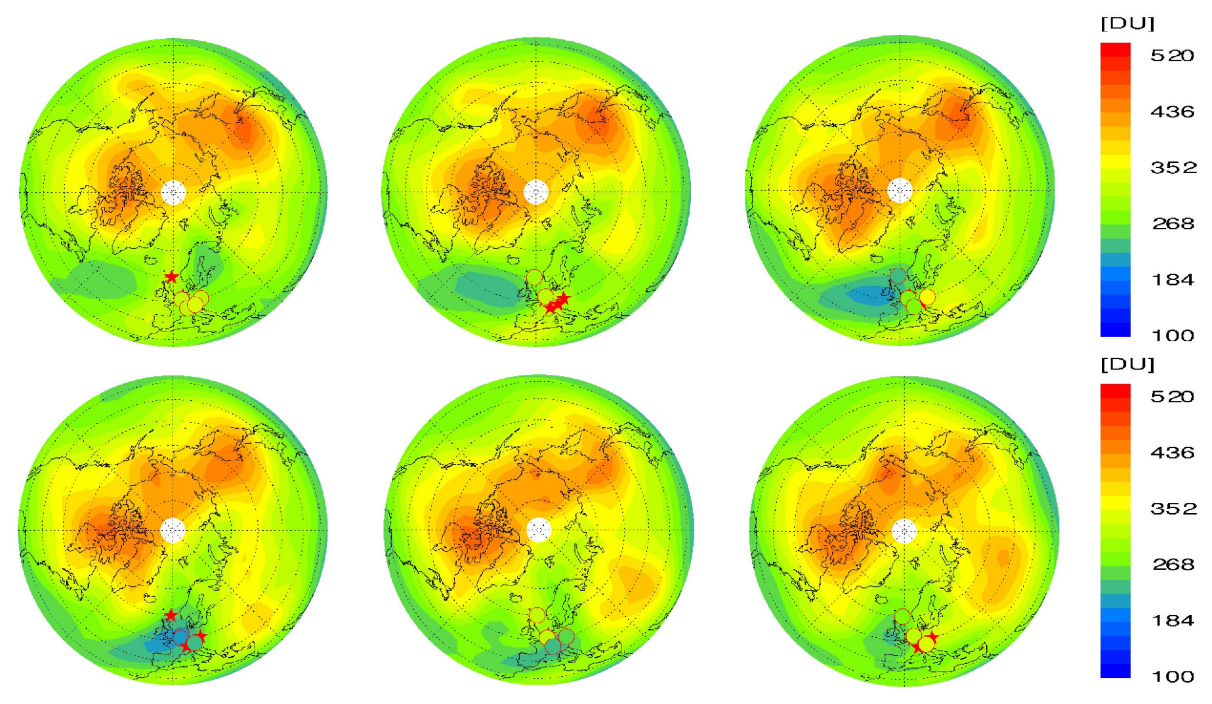

Fig. 8. Total ozone column in DU for 16 to 18 (top row) and 19 to 21 (bottom row) January 2006, 12:00 UT, simulated by KASIMA; sounding stations are marked either by red stars (no measurement) or by red circles (total column measurement available, circles filled in respective colour code for Dobson Units). 

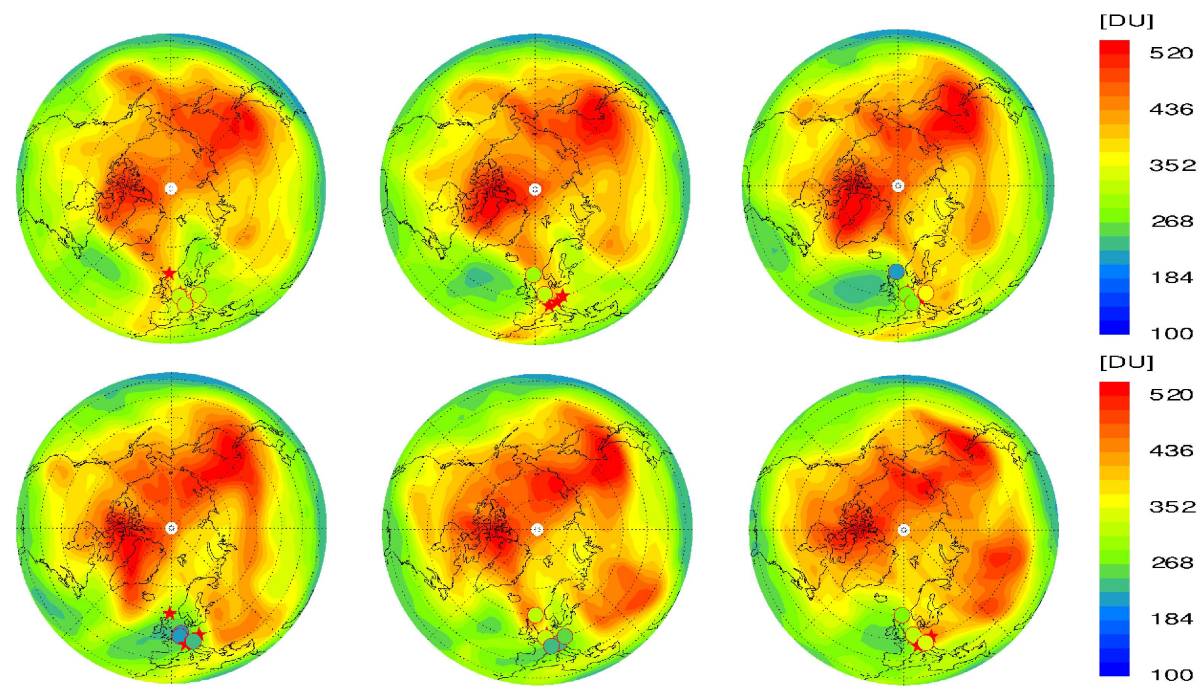

Fig. 9. Total ozone column in DU for 16 to 18 (top row) and 19 to 21 (bottom row) January 2006, 12:00 UT, simulated by E5/M1; sounding stations are marked either by red stars (no measurement) or by red circles (total column measurement available, circles filled in respective colour code for Dobson Units).

Table 4. Total and partial $(\Theta=350$ to $700 \mathrm{~K})$ ozone columns in Dobson Units (DU) as measured and simulated (for 12:00 UT) on the days of minimum ozone at the six ground stations.

\begin{tabular}{lccccccc}
\hline \multirow{2}{*}{ Station (day) } & \multicolumn{3}{c}{ Total Column Ozone } & \multicolumn{3}{c}{ Partial Column Ozone } \\
& Sonde & KASIMA & E5/M1 & Sonde & CLaMS & KASIMA & E5/M1 \\
\hline Lerwick (18) & 223 & 249 & 299 & 165 & 175 & 195 & 212 \\
De Bilt (19) & 206 & 223 & 247 & 130 & 139 & 163 & 154 \\
Uccle (19) & 205 & 224 & 246 & 93 & 119 & 163 & 148 \\
Hohpberg (20) & 237 & 247 & 269 & 117 & 142 & 179 & 164 \\
Payerne (20) & 227 & 238 & 249 & 133 & 155 & 160 & 126 \\
Prague (20) & 250 & 257 & 291 & 145 & 158 & 182 & 183 \\
\hline
\end{tabular}

Regarding the exact values for measured and modelled total column ozone (Table 4), both KASIMA and E5/M1 overestimated the observed values. KASIMA was closer to the measurements (between 3 and 12\% difference) than E5/M1 (between 10 and 34\% difference). The values for the partial ozone column revealed that all models clearly overestimated the ozone column between $\Theta=350$ and $700 \mathrm{~K}$, in particular at Uccle on 19 January. CLaMS was closest to the measurements (between 6 and 28\% difference), and KASIMA and E5/M1 both revealed high biases between 18\% (KASIMA for Lerwick and E5/M1 for De Bilt) and 75\% (KASIMA for Uccle). But also a slight underestimation of 5\% was simulated by E5/M1 for Payerne on 20 January.

\subsection{Ozone mixing ratios}

The ozone mixing ratios simulated by CLaMS are shown in Fig. 10 for the $\Theta=350$ and $600 \mathrm{~K}$ level. The evolution of the ozone mixing ratios on the $\Theta=350 \mathrm{~K}$ level indicates that ozone-poor low-latitude air masses were transported in the
UTLS region from southwesterly directions towards Western Europe in nice agreement with the patterns for potential vorticity on $\Theta=325 \mathrm{~K}$ for the same period (see Fig. 5). The evolution of the ozone mixing ratios on the $\Theta=600 \mathrm{~K}$ level (Fig. 10, bottom row) shows that the ozone concentration within the polar vortex was low and that the vortex moved over Western and Middle Europe during the low total ozone episode. The $\Theta=600 \mathrm{~K}$ level represented the altitude where the decrease of the ozone mixing ratio, according to the measured profiles at Uccle and Payerne was most severe (see Figs. 2 and 3, respectively). The respective simulations for the $\Theta=350$ and $600 \mathrm{~K}$ level by KASIMA and E5/M1 show qualitatively the same patterns and are not displayed here.

The simulated and measured ozone profiles are compared for the six stations and the three models in Fig. 11 for the days when minimum total ozone was observed. The respective model profile values were retrieved from the 12:00 UT simulations by linear interpolation between the four model grid points surrounding the station's location. CLaMS simulated the measured profiles generally well. Both features 

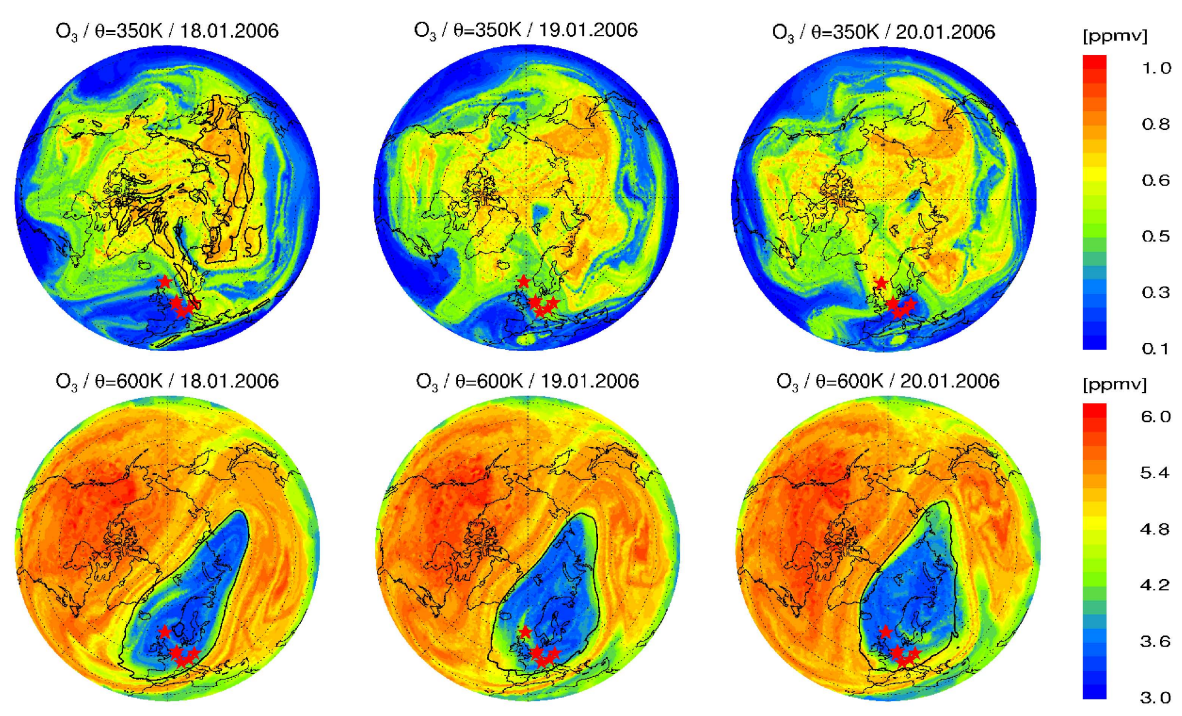

Fig. 10. Ozone mixing ratio in ppmv for 18,19 and 20 January 2006, $12: 00 \mathrm{UT}$, for $\Theta=350$ (top row) and $\Theta=600 \mathrm{~K}$ (bottom row) as simulated by CLaMS; ozone sounding stations marked by stars; boundary of the polar vortex marked by the thick black line; note the different scales for $\Theta=350$ and $600 \mathrm{~K}$.
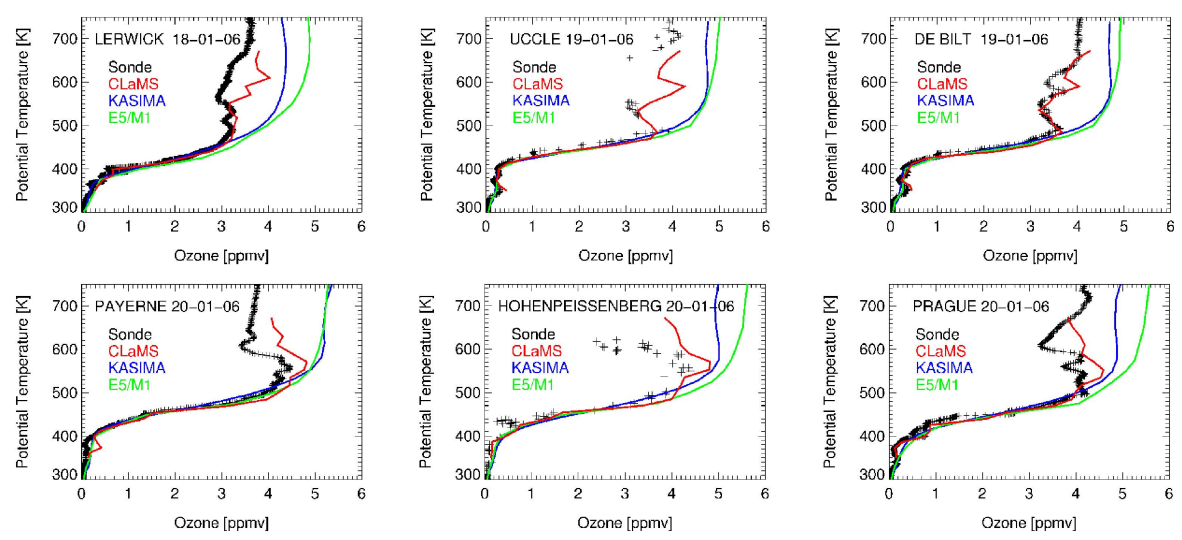

Fig. 11. Measured and simulated ozone profiles for the six ozone sounding stations, for the days when minimum total ozone was observed; ozone sonde data given by black crosses, CLaMS results by red, KASIMA results by blue, and E5/M1 results by green lines, respectively.

in the lower stratosphere and the low ozone values in the mid-stratosphere were captured. Above about $\Theta=550 \mathrm{~K}$, CLaMS overestimated the ozone mixing ratio. Up to around $\Theta=450 \mathrm{~K}$, both KASIMA and E5/M1 simulated the ozone mixing ratio generally well and agreed with CLaMS. At higher altitudes, KASIMA and E5/M1 did not capture the distinct ozone reduction, and the simulated ozone mixing ratios were distinctly higher than the CLaMS values. Comparing KASIMA and E5/M1, E5/M1 revealed generally higher mixing ratios than KASIMA, in particular over Lerwick, Hohenpeissenberg, and Prague. On the other hand, over Uccle, De Bilt, and Payerne, these two models agreed well. As CLaMS was run in the no-chemistry mode, the good agreement between observations and CLaMS ozone values is a clear sign for the prevalence of dynamic processes being re- sponsible for that extreme low total ozone event. In the discussion section we will further elaborate on the discrepancies between the models.

\subsection{Chemical species}

In order to evaluate the possibility of a contribution of instantaneous, in-situ chemical ozone depletion to the very low total ozone episode, KASIMA results for simulated active chlorine $\left(\mathrm{ClO}_{x}\right.$, i.e., $\left.\mathrm{Cl}+\mathrm{ClO}+2 \times \mathrm{Cl}_{2} \mathrm{O}_{2}\right)$ and ozone variation due to chemistry (i.e., also non-halogen reactions taken into account) are shown in Fig. 12. These KASIMA ozone variations are the cumulated chemical changes of ozone over $24 \mathrm{~h}$ at each model grid point. Changes induced by transport are neglected. In Fig. 13, E5/M1 results for simulated mixing ratios of active chlorine and the reservoir gases $\mathrm{HCl}$ 


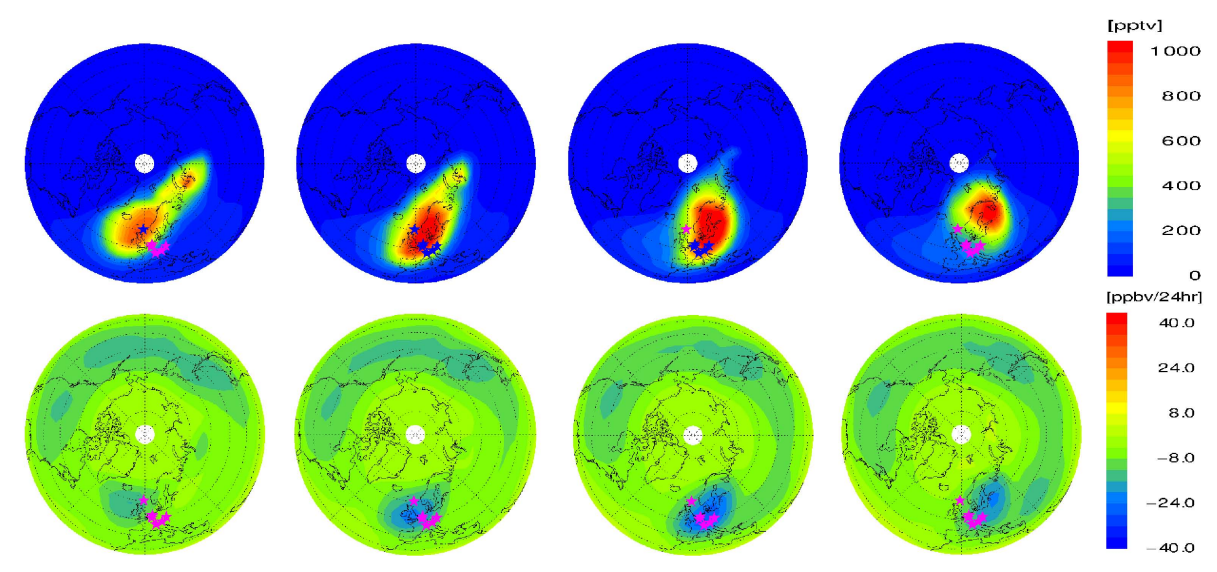

Fig. 12. $\mathrm{ClO}_{\mathrm{x}}$ (top row) and over $24 \mathrm{~h}$ cumulated chemical ozone change (bottom row) as simulated by KASIMA for 17 to 20 January 2006, 12:00 UT, for the $23.5 \mathrm{~km}$ height level (around $\Theta=500 \mathrm{~K}$ ); the six sounding stations are marked by stars (different colours for better visibility).

and $\mathrm{ClONO}_{2}$ are presented. Active chlorine in E5/M1 comprises $\mathrm{Cl}, \mathrm{ClO}, 2 \times \mathrm{Cl}_{2} \mathrm{O}_{2}, \mathrm{HOCl}, \mathrm{OClO}$, and $2 \times \mathrm{Cl}_{2}$. If chemical ozone destruction had indeed happened during the low ozone episode, this would be indicated by available active chlorine.

Considering the evolution of active chlorine between 17 and 20 January, represented by $\mathrm{ClO}_{\mathrm{x}}$ at $23.5 \mathrm{~km}$ altitude (KASIMA) and $\Theta=500 \mathrm{~K}$ (E5/M1), it clearly can be seen that a layer of active chlorine moved over the sounding stations. KASIMA simulated a peak of $\mathrm{ClO}_{\mathrm{x}}$ around 18 and 19 January, corresponding nicely with the region of adiabatic uplift and thus cooling of air masses. The simulated chemical ozone change (Fig. 12, bottom row) revealed in good agreement with the $\mathrm{ClO}_{\mathrm{x}}$ results an increasing $(17,18$ January), peaking (19 January) and decreasing (20 January) chemical ozone reduction over the same region. On the contrary, E5/M1 simulated not only higher $\mathrm{ClO}_{\mathrm{x}}$ mixing ratios, but also the area of active chlorine filled nearly the whole vortex.

Further analyses of KASIMA and E5/M1 revealed that, before the low total ozone event took place, within the polar vortex there was always active chlorine between $\Theta=450 \mathrm{~K}$ and $\Theta=550 \mathrm{~K}$. Before 17 January and after 20 January, KASIMA simulated between 0.1 and 0.3 ppbv $\mathrm{ClO}_{\mathrm{x}}$ at the $\Theta=500 \mathrm{~K}$ level at the six stations. These values increased to around $1.0 \mathrm{ppbv}$ during the event. Before 17 January and after 20 January, E5/M1 simulated similar, but slightly higher $\mathrm{ClO}_{\mathrm{x}}$ values than KASIMA. During the event, E5/M1 modelled between 1.9 and $2.2 \mathrm{ppbv}$ active chlorine at $\Theta=500 \mathrm{~K}$ above the stations. At the other altitude levels, the $\mathrm{ClO}_{\mathrm{x}}$ mixing ratio and also the chemical ozone reduction levels were distinctly lower. The discrepancy might mainly be explained by the different nudging schemes leading to slightly different dynamcis in the models and different chemistry schemes (e.g., calculation of the actinic fluxes), causing differences in chlorine activation.
As active chlorine was always present within the vortex, it is interesting to investigate the possibility of additional chlorine activation during the low total ozone event due to the vertical uplift of isentropes (triggering cooling and possible PSC formation). The evolution with time of the reservoir gases $\mathrm{ClONO}_{2}$ and $\mathrm{HCl}$ for the $\Theta=500 \mathrm{~K}$ level, as simulated by E5/M1, are shown in Fig. 13. Similar to the KASIMA simulations for $\mathrm{ClO}_{\mathrm{x}}$ and the chemical ozone change, the area distinctly depleted of the reservoir gases moved from the North Atlantic towards Eastern Europe, corresponding again nicely with the region of adiabatic uplift and thus cooling of air masses. The reduction of the chlorine reservoir gases and therefore the liberation of active chlorine increased towards 19 January 2006, reaching a peak on that day and decreasing afterwards. As the release of chlorine on stratospheric cloud particles largely follows the reaction $\mathrm{ClONO}_{2}+\mathrm{HCl} \rightarrow \mathrm{Cl}_{2}+\mathrm{HNO}_{3}$, (e.g., Solomon, 1999), it is not surprising that the area of depleted $\mathrm{ClONO}_{2}$ and $\mathrm{HCl}$ agreed very well. Both $\mathrm{ClONO}_{2}$ and $\mathrm{HCl}$ were reduced to 10 to 20 pptv over Western Europe.

These findings indicate that indeed additional chlorine activation occurred as a consequence of adiabatic uplift, inducing a local and short-term, additional in-situ chemical ozone depletion around 19 January. The total simulated chemical ozone change (maximum between -40 and $-30 \mathrm{ppbv} / 24 \mathrm{~h}$ on 19 January at $23.5 \mathrm{~km}$ ) is, however, far from being sufficient to explain the observed extreme ozone decrease around that date (see Figs. 2 and 3).

\section{Quantification of the ozone decrease}

\subsection{Ozone decrease at the different ozone sounding sta- tions and at different height levels}

As reference for calculating the ozone reduction on the days of minimum total ozone column at the six sounding stations 

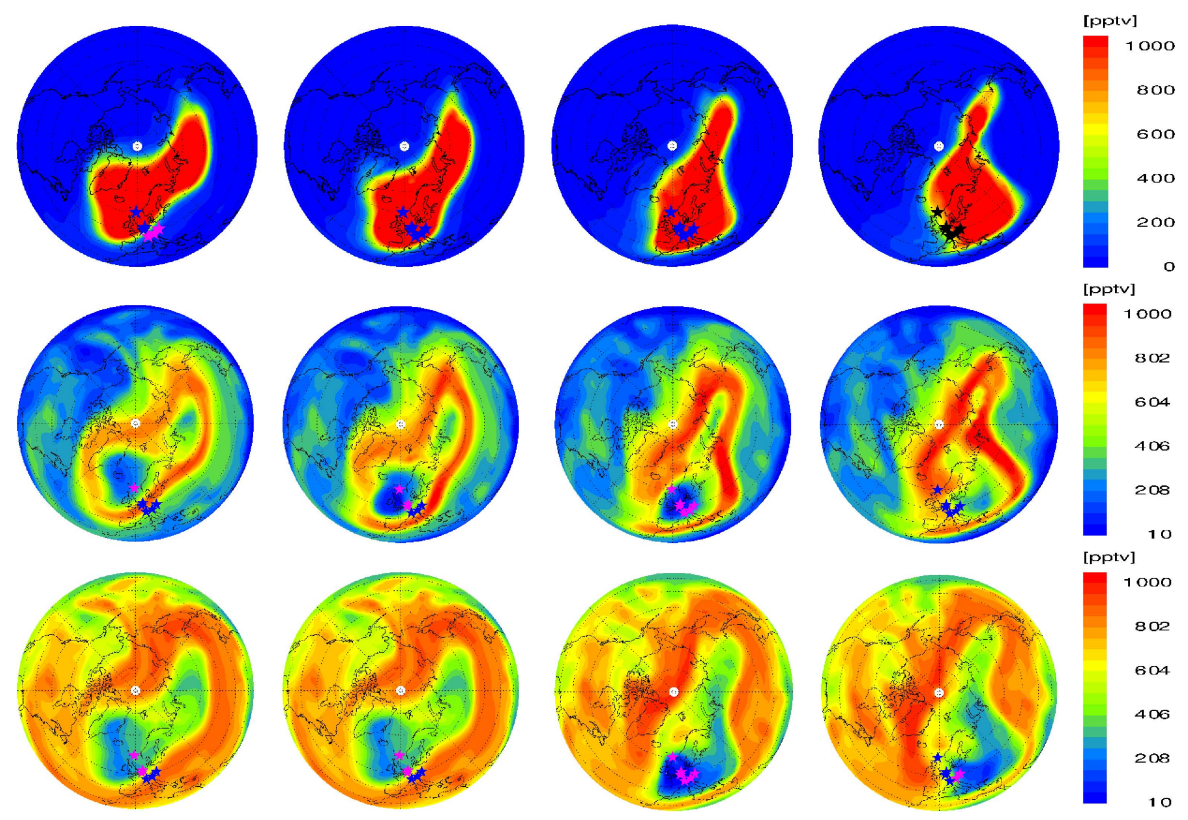

Fig. 13. Active Chlorine $\left(\mathrm{ClO}_{\mathrm{x}}\right.$, top row), chlorine nitrate $\left(\mathrm{ClONO}_{2}\right.$, middle row) and hydrochloric acid (HCl, bottom row) as simulated by E5/M1 for 17 to 20 January 2006, 12:00 UT, for $\Theta=500 \mathrm{~K}$; the six sounding stations are marked by stars (different colours for better visibility).

we took the average measured profile of all available ozone soundings at the respective station in January 2006 before the time window of the event (18 to 20 January).

The ozone column decrease for the six stations was calculated in Dobson Units within certain Theta-level intervals covering the range from $\Theta=300 \mathrm{~K}$ to $\Theta=750 \mathrm{~K}$ (Fig. 14). The interval step was $25 \mathrm{~K}$ potential temperature up to $\Theta=600 \mathrm{~K}$, and $50 \mathrm{~K}$ potential temperature above. Using potential temperature instead of pressure allows a more precise vertical assignment of the effects of the uplift of air masses to the evolution of the low total ozone event. The levels $\Theta=300 \mathrm{~K}$ (around $8 \mathrm{~km}, 360 \mathrm{hPa}$ ) and $750 \mathrm{~K}$ (around $30 \mathrm{~km}$, $10 \mathrm{hPa}$ ) were chosen considering that the contributions of the ozone concentration beyond these limits to the total ozone column were always below $5 \%$ and thus can be neglected with respect to the ozone column decrease investigated here. In addition, reliable ozone sonde data above $\Theta=750 \mathrm{~K}$ became distinctly sparser.

In the individual graph for each station, the integral of the measured ozone column decrease between $\Theta=300 \mathrm{~K}$ and $\Theta=750 \mathrm{~K}$ is indicated. It was strongest at Uccle and De Bilt with 108 and 103 DU, respectively, and somewhat lower at Hohenpeissenberg, Payerne, Prague and Lerwick with 85, 84,83 , and $74 \mathrm{DU}$, respectively. From the sonde measurements it became obvious that the ozone reduction extended over the whole altitude band from the upper troposphere to the upper limit of the mid-stratosphere.

A subjective differentiation of the observed ozone column change into two distinct height levels might be derived from the graphs, i.e. below and above around $\Theta=450$ to $500 \mathrm{~K}$, varying from station to station, most clearly for Payerne and Prague, and the least clearly for Hohenpeissenberg. At all stations, the ozone change in DU above around $\Theta=500 \mathrm{~K}$ was more pronounced than the ozone change below that Theta-level. Consistently for all stations, there was one peak between $\Theta=350$ and $400 \mathrm{~K}$, and another peak between $\Theta=600$ and $650 \mathrm{~K}$. In addition, at all stations the sonde measurements revealed an ozone increase in the lowest interval $(\Theta=300$ to $325 \mathrm{~K})$. This interval covered the tropopause region, and in spite of the influx of ozone poor low-latitude air masses (Figs. 2, 3, and 5), the lifting of the tropopause with the related temperature and pressure profiles (Fig. 4) led to an effective increase in the partial ozone column for that Thetainterval.

The comparison between measurements and the model results revealed that all models underestimated the ozone reduction measured by the sondes (compare Fig. 11). Often, CLaMS showed the best agreement with both absolute values and the relative distribution. However, there were cases (e.g., Payerne below $\Theta=500 \mathrm{~K}$ ) where the other two models performed better. KASIMA captured well the qualitative distribution, but not the absolute ozone change values, especially above $\Theta=500 \mathrm{~K}$ (e.g., at Lerwick, De Bilt and Uccle). Whereas E5/M1 simulated the relative distribution of the ozone change in good agreement with the sondes values, this model revealed more often pronounced deviations from the observations than the other models (e.g., distinct underestimation of the ozone column decrease at Lerwick and Prague below around $\Theta=450 \mathrm{~K}$ ). 

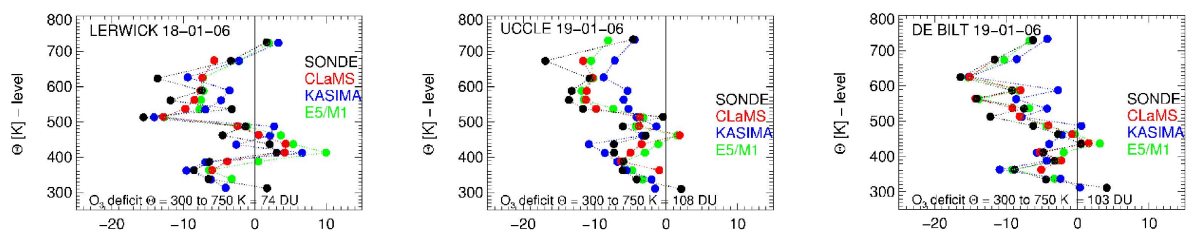

$\mathrm{O}_{3}$ change relative to reference, $\mathrm{DU}$
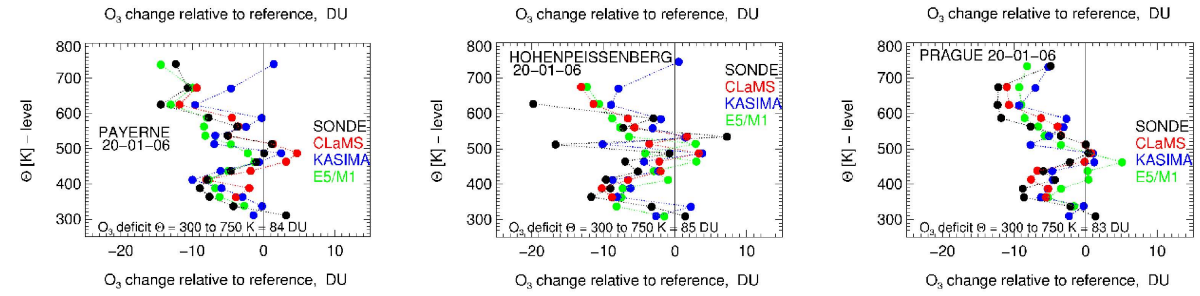

Fig. 14. Calculated ozone change in DU relative to the reference profiles, for observed (black points) and simulated (CLaMS=red, $\mathrm{KASIMA}=$ blue, $\mathrm{E} 5 / \mathrm{M} 1=$ green points) ozone profiles at the six stations and the days of observed minimum total ozone; dotted lines for guiding the eye; negative values correspond to lower (reduction), positive values to higher (gain) values than the reference; values integrated between certain Theta-level intervals (details see text).

\subsection{Quantification of responsible mechanisms for the ozone column decrease}

\subsubsection{Contribution of the dynamic mechanisms below and above $\Theta=450 \mathrm{~K}$}

It was demonstrated above that dynamic mechanisms played an important role for the formation of the very low total ozone episode. On the one hand, the ozone-depleted stratospheric polar vortex was displaced over the concerned region. On the other hand, in the UTLS region ozone-poor low-latitude air was advected, connected with net-divergence of mass induced by the uplift of isentropes in the lower stratosphere. In this section, the ozone change at different height levels is attributed to these two mechanisms.

The integrated ozone change between $\Theta=300$ and $450 \mathrm{~K}$ was considered to be caused by advection of ozone-poor low-latitude air masses connected with vertical displacement of isentropes. The integrated ozone reduction between $\Theta=450$ and $750 \mathrm{~K}$ was considered to be caused by the influence of the ozone-poor polar vortex. The $\Theta=450 \mathrm{~K}$ level ( 50 to $60 \mathrm{hPa}, 19$ to $20 \mathrm{~km}$ ) has been chosen because of the following consideration. The ozone change profiles in Fig. 14 support a somewhat subjective differentiation into two distinct height levels (below and above around $\Theta=450$ to $500 \mathrm{~K}$ ). From Fig. 4 it is evident that the influence of the uplift of isentropes on the ozone decrease reached altitudes between $\Theta=500$ and $600 \mathrm{~K}$ (around 21 to $25 \mathrm{~km} ; 40$ to $20 \mathrm{hPa}$ ). However, $\Theta=500 \mathrm{~K}$ was clearly in the midstratosphere where the polar vortex influence was already significant. Choosing this or a higher potential temperature level as delimitation would mean to attribute a significant part of the polar vortex displacement to the other responsible mechanism. On the other hand, the deficit above $\Theta=450 \mathrm{~K}$ included also a decrease induced by the uplift of isentropes. But, it took place in polar vortex air. Therefore, separating at a certain height level will always be a compromise which has to be taken into account when interpreting the results. Taking the $\Theta=450 \mathrm{~K}$ level assures that in the lower altitude compartment, which comprised certainly the lower stratosphere and not yet the mid-stratosphere, the influences of the lifting of the tropopause and the advection of low-latitude air masses were included and that in the upper altitude compartment the effect of the polar vortex displacement was included. In addition, James and Peters (2002) reported the average limit of the influence of the polar vortex during low total ozone epidsodes to be around $70 \mathrm{hPa}$ over Western and Middle Europe.

In Fig. 15, the influence of the two dynamic processes mentioned above on the total ozone decrease is quantified for each of the six stations. The quantification (i.e. integration of the ozone change between $\Theta=300$ and $450 \mathrm{~K}$, and between $\Theta=450$ and $750 \mathrm{~K}$, respectively) was done both for the measurements and the model results, comparing each time the measured and simulated ozone profile against the measured reference profile. Likewise the sonde observations, KASIMA results were available for the total column from $\Theta=300$ to $750 \mathrm{~K}$ (assigned Total in the graphs of Fig. 15). In the case of CLaMS and E5/M1, values for the lowest or uppest Theta-level interval were not consistently available for all stations. Therefore, the range $\Theta=350$ to $700 \mathrm{~K}$ was chosen to consistently compare models with the sonde measurements (assigned Partial in the graphs of Fig. 15).

Considering the sonde-based results, it is obvious that at De Bilt, Lerwick and Uccle the influence of the polar vortex displacement dominated clearly the other mechanism. Also at Prague, Payerne and Hohenpeissenberg the polar vortex impact prevailed, however, less clearly. Comparing the model results to the measurements, it is clear that all models distinctly underestimated the total ozone decrease. CLaMS was able to reproduce well the relative importance of the two mechanisms at all stations. KASIMA reproduced a general, 

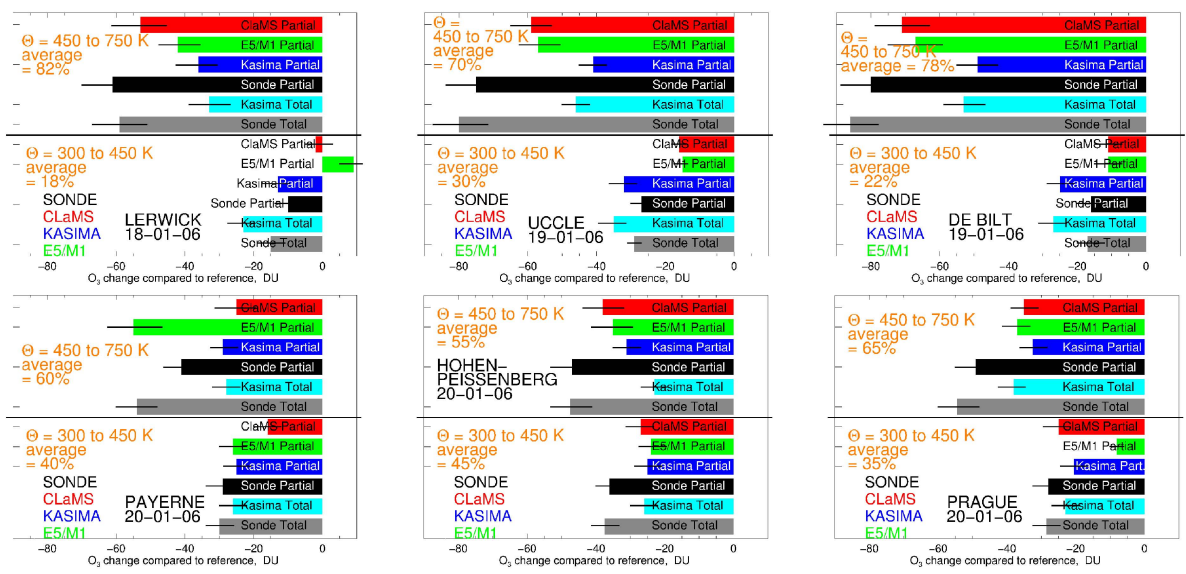

Fig. 15. Integrated ozone change between $\Theta=300$ and $450 \mathrm{~K}$, and between $\Theta=450$ and $750 \mathrm{~K}$ at the six stations; sonde measurements in black and grey, KASIMA in blue and light blue, E5/M1 in green, CLaMS in red; Partial results for consistent common range $(\Theta=350$ to $700 \mathrm{~K}$ ); sonde and KASIMA also available for Total column between $\Theta=300$ and $750 \mathrm{~K}$; average relative weights in $\%$ of the two altitude compartments to the total ozone decrease also given.

Table 5. Integrated ozone change between $\Theta=300$ and $450 \mathrm{~K}$, and between $\Theta=450$ and $750 \mathrm{~K}$, as displayed in Fig. 15 for the six stations; values given for day of observed minimum total ozone column; _P: results for the consistent common range $(\Theta=350$ to $700 \mathrm{~K})$; _T: sonde and KASIMA results also for the total column $(\Theta=300$ to $750 \mathrm{~K})$.

$\Theta=300$ to $450 \mathrm{~K}$ (low-latitude air, adiabatic uplift) $/ \Theta=450$ to $750 \mathrm{~K}$ (polar vortex)

Dobson Units

\begin{tabular}{lcccccc} 
station (day) & Sonde_T & KASIMA_T & Sonde_P & KASIMA_P & E5/M1_P & CLaMS_P \\
\hline Lerwick (18) & $-15 /-59$ & $-23 /-33$ & $-10 /-61$ & $-13 /-36$ & $+9 /-42$ & $-2 /-53$ \\
De Bilt (19) & $-17 /-86$ & $-27 /-53$ & $-16 /-80$ & $-25 /-49$ & $-11 /-67$ & $-11 /-71$ \\
Uccle (19) & $-29 /-80$ & $-35 /-46$ & $-27 /-75$ & $-32 /-41$ & $-15 /-57$ & $-16 /-59$ \\
Hohpberg (20) & $-37 /-48$ & $-26 /-23$ & $-36 /-47$ & $-25 /-31$ & $-24 /-35$ & $-27 /-38$ \\
Payerne (20) & $-30 /-54$ & $-26 /-28$ & $-29 /-41$ & $-25 /-29$ & $-26 /-55$ & $-16 /-25$ \\
Prague (20) & $-28 /-55$ & $-23 /-38$ & $-28 /-49$ & $-20 /-33$ & $-8 /-37$ & $-25 /-35$ \\
\hline
\end{tabular}

but less pronounced, dominance of the impact of the polar vortex displacement. At Prague, Payerne and Hohenpeissenberg, the stations where the polar vortex dominance was less distinct, KASIMA agreed well with the sondes below $\Theta=450 \mathrm{~K}$. The CCM E5/M1 simulated the relative importance of the two mechanisms generally well. But, at some stations, E5/M1 simulated very differing result from the other models and the sonde measurements (e.g., over-estimation of the ozone deficit at Payerne above $\Theta=450 \mathrm{~K}$; underestimation at Prague below $\Theta=450 \mathrm{~K}$; no overall ozone decrease at Lerwick below $\Theta=450 \mathrm{~K}$ ). The partial ozone column reductions in DU displayed in Fig. 15 are listed in Table 5. In Fig. 15, the overall averages of the relative weights in per cent of the two altitude compartments are given, representing the two dynamic processes responsible for the evolution of the very low total ozone episode. The percentages for each station were calculated by first taking for both the sonde measurements and the three model simulations the respective integrated ozone column change between $\Theta=300$ and $750 \mathrm{~K}$ as basis for the calculation of the relative fractions of measured and modelled partial ozone decrease for the two height compartments $(\Theta=300$ to $450 \mathrm{~K}$, and $\Theta=450$ to $750 \mathrm{~K})$, respectively. Second, in order to calculate the overall average for each station, all relative fractions for measurement and model results were taken.

The displacement of the ozone-depleted polar vortex caused around $80 \%$ of the total ozone column reduction at De Bilt and Lerwick, and on average $70 \%$ at Uccle. Also, over Prague, Payerne and Hohenpeissenberg the polar vortex influence was dominant, however, less than at the other stations. It accounted for around two-thirds over Prague, 60\% on average over Payerne, and over Hohenpeissenberg $55 \%$ on average, compared to the other mechanism (advection of ozone-poor low-latitude air masses connected with uplift of isentropes). If only the sonde measurements were considered, the pattern would not change much, only the polar vortex impact would gain a few percent points at De Bilt, Payerne, and Uccle. 
Table 6. Contribution in $\%$ of the influence of pressure changes on isentropes to the ozone column decrease within the layer $\Theta=300$ to $450 \mathrm{~K}$, for the six stations and the day of observed minimum of the total ozone column.

\begin{tabular}{lccccc}
\hline station (day) & Sonde & CLaMS & KASIMA & E5/M1 & mean \\
\hline Lerwick (18) & 57 & 70 & 47 & 56 & 57 \\
De Bilt (19) & 58 & 72 & 55 & 63 & 62 \\
Uccle (19) & 33 & 52 & 38 & 48 & 43 \\
Hohpberg (20) & 39 & 42 & 32 & 41 & 38 \\
Payerne (20) & 32 & 38 & 27 & 26 & 31 \\
Prague (20) & 41 & 47 & 44 & 54 & 46 \\
\hline
\end{tabular}

With respect to the uncertainty estimation for these relative weights, one has to take into account the uncertainties of the sonde measurements, their repercussions on calculating the reference profiles which in return are used for calculating the ozone column change for both sonde measurements and model simulations, and also the uncertainties related to the models ozone mixing ratios, and temperature and pressure profiles. This led to error estimations between 15 and $25 \%$ for the total ozone decrease, depending on station, date, sonde, or model. Therefore, only at De Bilt, Lerwick, and Uccle the dominance of the polar vortex influence on the low total ozone event was significant. At Payerne, Prague, and Hohenpeissenberg, this dominance was not significant.

\subsubsection{Influence of uplift of isentropes and pressure change}

In order to better separate the contributions of horizontal and vertical transport processes to the low total ozone event, the effects of advection of ozone-poor low-latitude air masses and vertical displacement of isentropes were distinguished within the layer $\Theta=300$ to $450 \mathrm{~K}$. To this end, the respective ozone column decrease caused by the pressure change on isentropes was investigated.

To estimate that influence, mean ozone mixing ratios (calculated from the respective ozone soundings in January 2006 before the event, at the six stations) on the six Theta-levels between $\Theta=300$ to $450 \mathrm{~K}$ were converted to partial pressures using the actual pressure on the respective isentrope on the respective day of observed minimum total ozone. Whereas the mean ozone mixing ratios were always the observed ones, the actual pressures were taken from the soundings and the models, respectively, in order to estimate specifically the pressure impact for both the observations and the models. These converted ozone partial pressures were subtracted from the partial pressures calculated with the respective observed mean pressures on the Theta-levels. The difference was then converted to Dobson Units and compared to the measured ozone column decrease on the Theta-levels. Finally, we calculated for both soundings and models the over-
Table 7. Cumulated chemical ozone depletion as simulated by KASIMA; values given in DU.

Chemical ozone reduction modelled by KASIMA (DU; $\Theta=300$ to $750 \mathrm{~K}$ )
\begin{tabular}{lccccc} 
Lerwick & De Bilt & Uccle & Hohenpeissenberg & Payerne & Prague \\
\hline $0.74^{\mathrm{a}}$ & $0.96^{\mathrm{b}}$ & $0.96^{\mathrm{b}}$ & $1.42^{\mathrm{c}}$ & $1.27^{\mathrm{c}}$ & $1.51^{\mathrm{c}}$ \\
\hline a 17 and 18 January 2006 & & & \\
b 18 and 19 January 2006 & & & \\
c 18 to 20 January 2006
\end{tabular}

all (i.e. the average from the six Theta-levels) percentage contribution to the ozone column decrease within the layer $\Theta=300$ to $450 \mathrm{~K}$ (see Table 6).

This percentage contribution varied between 26\% (Payerne, E5/M1) and 72\% (De Bilt, CLaMS). The influence of pressure change was weakest at Payerne (mean $=31 \%$ ) and strongest at De Bilt and Lerwick (62\% and 57\%, respectively). In general, the three models revealed higher contributions than observed by the ozone soundings. This can be explained by differences between modelled and observed pressure fields. The overall mean contribution of pressure change to the ozone column decrease, calculated from ozone soundings and models, is $46 \%$. That influence of the pressure change was not constant over height. In the layer $\Theta=300$ to $400 \mathrm{~K}$, the mean contribution was $31 \%$, whereas it was $66 \%$ within $\Theta=400$ to $450 \mathrm{~K}$. This indicates that the advection of ozone-poor low-latitude air masses had its strongest impact around the tropopause and in the lowest part of the lower stratosphere.

The mean contribution at the respective stations (see Table 6) was then taken to calculate the respective fraction in DU of the observed integrated ozone column change in the layer $\Theta=300$ to $450 \mathrm{~K}$ (see Table 5). This amount in DU was then compared to the total ozone column reduction at the respective station. It became obvious that the influence of pressure change on isentropes contributed between 10\% (De Bilt) and 16\% (Hohenpeissenberg) to the total ozone column reduction. Compared to the horizontal transport processes (i.e. advection of ozone-poor low-latitude air masses and displacement of the polar vortex), the influence of vertical transport processes was therefore only of minor importance.

\subsubsection{Impact of chemistry}

In order to quantify the contribution of instantaneous, in-situ chemical ozone depletion to the very low total ozone episode, the respective KASIMA results were considered. In Table 7, the chemical ozone change as simulated by KASIMA for the six ozone sounding stations is listed. For the calculation, the cumulated chemical ozone change between $\Theta=300$ and $750 \mathrm{~K}$ was integrated. As the timescale for chemical ozone depletion of about $5 \mathrm{DU}$ in the mid-stratosphere is at least in the order of days (assuming rather high ozone loss 
rates, e.g. Becker et al., 1998; Harris et al., 2002), the simulated chemical ozone change was integrated for all stations at least over $48 \mathrm{~h}$ around the day of observed total ozone minimum. It added up to between 0.7 DU at Lerwick and 1.5 DU at Prague. Over $80 \%$ of it took place above $\Theta=450 \mathrm{~K}$, and around two-thirds in the layer between $\Theta=450$ and $550 \mathrm{~K}$.

Comparing the values between $0.7 \mathrm{DU}$ and $1.5 \mathrm{DU}$ for the ozone variation due to chemistry with the overall ozone column decrease described above, it becomes obvious that ozone chemistry contributed a traceable but very marginal part. Depending on station and on observation or model simulation as reference for the overall ozone decrease, the fraction of the ozone variation due to chemistry varied between 1 to $3 \%$. The overall average was $2 \%$. To estimate the error, one has to consider the uncertainties of the sonde measurements (between 5 and $17 \%$, depending on altitude), of the models' ozone mixing ratios, temperature, and pressure profiles, and of the cumulated chemical ozone depletion simulated by KASIMA. The final error for the cumulated chemical ozone depletion may thus be estimated to be around $50 \%$. The absolute amount in DU of instantaneous, in-situ chemical ozone depletion was thus within the overall error of calculating the total ozone column (see Sect. 2).

\section{Discussion}

In order to distinguish between the two main dynamic mechanisms responsible for the low total ozone event, the $\Theta=450 \mathrm{~K}$ level was chosen and reasoned in Sect. 6. It is clear that shifting this altitude vertically will affect the final calculated relative weight of the two mechanisms. In order to investigate the sensitivity towards a shift of the altitude delimitation, we re-calculated, as described in Sect. 6, the respective relative contributions by shifting the delimitation down to $\Theta=425 \mathrm{~K}$ (around $70 \mathrm{hPa}$ ), and up to $\Theta=500 \mathrm{~K}$ (around $40 \mathrm{hPa}$ ), respectively. The overall sensitivity found was a variation of the relative weight of the two mechanisms by \pm 8 percentage points averaged over all six stations.

In their analysis of the January 2006 low total ozone episode over the UK, Keil et al. (2007) split the ozone profile at Lerwick in two layers (surface to $65 \mathrm{hPa}$ and 65 to $10 \mathrm{hPa}$ ), however, without mentioning reasons for the $65 \mathrm{hPa}$ (around $\Theta=420$ to $440 \mathrm{~K}$ ) delimitation. They concluded that one third of the ozone column decrease could be attributed to the displacement of the ozone-depleted polar vortex and twothirds to the effects of the uplift of isentropes in the lower stratosphere together with the advection of ozone-poor lowlatitude air masses. This differing result to ours can mainly be attributed to the effect of using pressure instead of potential temperature as height coordinate for delimitation. We re-calculated the total ozone change for Lerwick, but now using pressure as height coordinate for calculating the reference profile and the ozone decrease, and using the $65 \mathrm{hPa}$ level as delimitation. This resulted in about $40 \%$ of the ozone column decrease having been caused by the displacement of the polar vortex, and the other $60 \%$ by the other mechanism, close to the results of Keil et al. (2007). This shows that the choice whether pressure or potential temperature are used as height coordinate has a large influence on quantifying the impact of the different mechanisms. Using potential temperature instead of pressure should allow a more precise vertical assignment of the responsible mechanisms to the evolution of the low total ozone event because it avoids averaging over different air masses caused by adiabatic fluctuations. Unfortunately, Keil et al. (2007) give no estimation of the total ozone decrease in DU.

The discrepancies between observations and the three models, but also among the models themselves are most likely due to differences in ozone initialisaton, spatial resolution, and treatment of the meteorological fields. In particular, CLaMS was initialised with January observational data from the Microwave Limb Sounder (on EOS AURA satellite), whereas KASIMA and E5/M1 were initialised with model data. Furthermore, CLaMS has been especially designed for describing the dynamics in the stratosphere and covers especially the altitudes of the climatological ozone maximum where the impact of the ozone decrease is strongest. In addition, as CLaMS was run in the no-chemistry mode, the good agreement between observations and CLaMS is a clear sign for a realistic initialisation of the CLaMS simulation, and for the predominance of dynamic formation processes during the evolution of that very low total ozone episode. The CTM KASIMA and the CCM E5/M1 cover a broader altitude range of the atmosphere what might go on the expense of the quality of reproduction of some features in the stratosphere. As E5/M1 is a nudged CCM, a different behaviour than CTMs can be expected, and that it performs at comparisons for certain locations not as well as CTMs. This might explain why the models, and especially KASIMA and E5/M1, reproduce qualitatively the low total ozone episode, but have difficulties to model it quantitatively, and to exactly locate it in time and space. A detailed comparison between the three models is beyond the scope of this work. Recently, Khosrawi et al. (2009) showed that CLaMS, KASIMA and E5/M1 are in good agreement with Odin/SMR and ILAS/ILAS-II satellite ozone retrievals. Differences were generally in the range of $\pm 20 \%$. However, the authors found an underestimation of polar winter ozone loss both for KASIMA and E5/M1.

That detectable but marginal in-situ chemical ozone destruction might have occurred was confirmed by Keckhut et al. (2007). They detected polar stratospheric clouds (PSC) over southern France during 18-20 January 2006 by lidar measurements and showed with CTM analyses that the predicted PSC area extended from Northwestern Europe southwards towards around $40^{\circ} \mathrm{N}$. The authors quantified the chemical ozone destruction by $35 \mathrm{ppbv} /$ day, temporally restricted to 18 and 19 January. This number is in very good agreement with the KASIMA results of maximum in-situ chemical ozone change between -40 and $-30 \mathrm{ppbv} / 24 \mathrm{~h}$ on 
19 January. However, a quantification of chemical ozone depletion during the winter 2005/2006 and its contribution to the ozone decrease within the polar vortex, is beyond the scope of this study. The Arctic winter 2005/06 is classified as one of the mildest on record with regard to the temperatures (WMO, 2006) and that report states that overall column ozone loss was on the order of $13 \%$ and that most of this loss occurred in January. However, it is important to stress that the chemical ozone depletion within the vortex was not the main reason for the formation of the low total ozone event. The event was caused by horizontal and vertical transport processes and only marginally by chemistry.

Hood et al. (2001) investigated with a transport model without chemistry 71 extreme low total ozone events (reduction $>100$ DU) between 1978 and 1999, also with respect to which extent chemical ozone loss contributed to their formation. They found that in-situ chemical ozone destruction accounted for less than $1 \%$ to the observed ozone column reductions and all extreme minima were thus consistent with a mainly dynamic origin. In the case of extreme minima, vertical transport processes contributed around $80 \mathrm{DU}$ and horizontal transport processes between 60 and $100 \mathrm{DU}$ to the ozone minima. This study, however, found distinctly lower contributions to the low total ozone event by the vertical displacement of isentropes.

There are further studies, investigating the relative importance of the main mechanisms leading to the formation of such low total ozone events. James et al. (2000) employed a linear ozone transport model using TOMS total ozone and ECMWF meteorological data from 1982 to 1992, and applied different polar vortex displacement scenarios, in order to study the influence of polar vortex displacements on very low ozone episodes in the winter Northern Hemisphere. Their results confirm that in the UTLS region the effects of the vertical displacement of isentropes, and to a minor part the advection of low-latitude air masses, dominate total ozone reduction in the case of very low ozone episodes. The impact of a polar vortex displacement is dominant in the midstratosphere. Our results, however, revealed that in the UTLS region the impact of vertical displacement of isentropes and advection of ozone-poor air masses were almost equally important. Our analysis is consistent with Koch et al. (2005) who found that the vertical transport processes provided an additional but less important contribution to low total ozone events compared to horizontal transport processes.

Distinct ozone minima in the lower stratosphere were analysed by Reid et al. (2000) by using long-time data records of six European ozone sounding stations. They found that the advection of ozone-poor subtropical air masses is linked to these minima and could reduce the total ozone column by 10 to $15 \%$. The authors analysed a distinct case in March 1997, when the intrusion of subtropical air masses combined with the effects of an uplift of isentropes reduced the total ozone column by around $40 \mathrm{DU}$.
Orsolini et al. (1995) performed a 7-day simulation of a low ozone event in late January 1992 over Northern Europe with a GCM treating ozone as passive tracer. Total column ozone was reduced as far as to $190 \mathrm{DU}$ over Latvia, with deviations from the climatological mean between 50 and $100 \mathrm{DU}$. The authors found that mainly long-range transport of ozone-poor subtropical air masses together with the uplift of isentropes up to at least $40 \mathrm{hPa}$ were responsible for the low total ozone values. In addition, polar vortex air was advected over that region. However, the authors did not explicitly quantify the relative contributions.

The understanding of distinct and sudden reductions of the ozone column is also relevant for impact studies of potentially harmful exposures of the human skin (e.g., WHO, 2002) or aquatic and terrestrial ecosystems (e.g., Biggs and Joyner, 1994) to unusually high levels of ultraviolet radiation. There are case studies about low total ozone events in late spring (Stick et al., 2006) or summer (Orsolini and Nikulin, 2006) when UV radiation could indeed reach harmful levels for human health. According to the categories of the World Health Organisation (WHO, 2002), the UV-index which is a dimensionless measure linking the intensity of UV radiation to the sensitivity of human skin, could be increased by such extreme ozone reduction during these seasons from levels burning the skin slowly to levels burning the skin fast. On the other hand, a distinct ozone reduction in mid-January over Western and Middle Europe will have low harming potential for the human skin because of the low elevation of the sun. The UV-index around noon for clear sky at Uccle on 19 January 2006 increased (assuming the reduction of the ozone column from normal 330 to $200 \mathrm{DU}$ ) from 0.51 to 0.86 . Although the UV-index increased by more than $50 \%$, an UV-index value below 1 is categorised as almost no skin burning. In addition, according to meteorological analyses (not shown), cloud coverage was high during 18 to 20 January 2006 over Western Europe, i.e. less UV radiation than for clear sky reached the ground.

\section{Conclusions}

The present study investigated in detail the very low total ozone episode around 19 January 2006 over Western Europe. On that day, the total ozone column over Uccle, Belgium, reached a daily minimum of $200 \mathrm{DU}$, the lowest value recorded at this site since beginning of the measurements in 1971. Similar, or even lower values were observed at other sites in Northern Europe (Keil et al., 2007). Data of (i) six ozone sounding stations (De Bilt, Hohenpeissenberg, Lerwick, Payerne, Prague, and Uccle), (ii) ECMWF meteorological fields, and (iii) two chemistry transport models (CLaMS with ozone as passive tracer, and KASIMA with included stratospheric chemistry), and a climate chemistry model (E5/M1, stratospheric chemistry included) were used in order to analyse the mechanisms responsible for the formation of that event. This work contributes to and extends 
the investigation of the formation processes of such very low total ozone episodes. The broad data basis allowed an unprecedented detailed quantification of the total ozone change on different height levels at different locations, and the determination to what extent different mechanisms were responsible for it.

At all six sounding stations the low total ozone episode was clearly observed between 18 January 2006 (at the most western station, Lerwick) and on 20 January 2006 at the most eastern one (Prague). The ozone column decrease between $\Theta=300$ and $750 \mathrm{~K}$ was strongest at Uccle and De Bilt with 108 and 103 DU, respectively, and somewhat lower at Hohenpeissenberg, Payerne, Prague, and Lerwick with 85, 84, 83 , and $74 \mathrm{DU}$, respectively. Compared to the normal total ozone column at the stations, this corresponded to reductions of $25 \%$ at Hohenpeissenberg, Payerne, Prague, and Lerwick, and of one third at De Bilt and Uccle.

On the one hand, the displacement of the ozone-poor polar vortex over the concerned region contributed to that very low total ozone episode. The displacement of the vortex was shown by potential vorticity fields at $\Theta=500 \mathrm{~K}$ from ECMWF analyses, and the very low ozone concentrations in the polar vortex were demonstrated both by observed ozone profiles (Figs. 2 and 3) and the simulated ozone mixing ratios at mid-stratospheric heights (Fig. 10). On the other hand, ozone-poor low-latitude air masses were advected from Southwest on the western flank of anticyclonic systems in the tropopause region (around $\Theta=300$ to $350 \mathrm{~K}$ ) related to blocking surface high pressure systems. This advection could be seen by both the evolution with time of the modelled partial and total ozone column (Figs. 7, 8 and 9, for CLaMS, KASIMA, E5/M1, respectively) and the ozone mixing ratio evolution on the $\Theta=350 \mathrm{~K}$ level (Fig. 10). Associated with these phenomena was an elevation of the tropopause and uplift of isentropes (Figs. 2, 3 and 4, observations from ozone soundings; as well as Fig. 5, potential vorticity fields at $\Theta=325 \mathrm{~K})$. Since air parcels move approximately adiabatically in the lower stratosphere, that uplift of isentropes led to lower ozone concentrations in those air parcels. As also the pressure difference between two isentropes decreased (see Sect. 3), and thus net-divergence of air out of the column compensated for the air parcel expansion, the total ozone column was decreased.

In Fig. 15, Tables 5 and 6, the dynamic processes responsible for the evolution of the low total ozone event are quantified for the sonde measurements and the model results. The displacement of the ozone-depleted polar vortex caused around $80 \%$ of the total ozone column reduction at De Bilt and Lerwick, and on average $70 \%$ at Uccle. Over Prague, Payerne and Hohenpeissenberg that influence was less dominant. It accounted for around two-thirds over Prague, $60 \%$ over Payerne, and 55\% over Hohenpeissenberg. The influence of vertical transport processes (pressure change on isentropes within $\Theta=300$ to $450 \mathrm{~K}$ ) contributed between $10 \%$ (De Bilt) and 16\% (Hohenpeissenberg) to the total ozone col- umn reduction and was therefore only of minor importance. The advection of ozone-poor low-latitude air masses had its strongest impact around the tropopause and in the lowest part of the lower stratosphere. Taking into account the error estimate for the total ozone change (15 to $25 \%$ ), and the uncertainties related to the calculation of the reference profiles and the delimitation of the two altitude compartments, only at De Bilt, Lerwick, and Uccle the dominance of the polar vortex influence was significant.

With respect to the comparison between measurements and models, all three models reproduced well the qualitative evolution and formation of the event. However, the models overestimated in general the ozone mixing ratios throughout the column, and in particular above $\Theta=550 \mathrm{~K}$. From the three models, CLaMS was closest to the observations and captured ozone peaks and lows over the modelled column. Up to around $\Theta=450 \mathrm{~K}$, both KASIMA and E5/M1 simulated the ozone mixing ratio generally well and agreed with CLaMS. At higher altitudes, KASIMA and E5/M1 did not capture the distinct ozone reduction, and the simulated ozone mixing ratios were distinctly higher than the CLaMS ones. Comparing KASIMA and E5/M1, E5/M1 revealed generally higher mixing ratios than KASIMA.

The in-situ chemical ozone reduction as simulated by KASIMA over 2 to 3 days around the event varied between 0.74 to $1.5 \mathrm{DU}$ (Table 7) for the six sounding stations. Compared to the overall ozone column decrease, it is obvious that ozone chemistry contributed a traceable but marginal role to the evolution of the low total ozone event. At all stations, the cumulated chemical ozone change occurred mainly in the mid-stratosphere, with over $80 \%$ above $\Theta=450 \mathrm{~K}$, and around two-thirds in the layer between $\Theta=450$ and $550 \mathrm{~K}$. Chemistry contributed between 1 to $3 \%$ to the calculated total ozone decrease, depending on station, and on observation or model simulation as reference for the overall total ozone change. The overall average was $2 \pm 1 \%$. The absolute amount in DU of the instantaneous, in-situ chemical ozone depletion was thus within the overall error of calculating the total ozone column.

This analysis demonstrated that mainly the displacement of the ozone depleted polar vortex contributed to the very low total ozone episode in January 2006. Vertical transport processes were found to be only of minor importance compared to the horizontal transport processes. However, statistically significant was only the dominant polar vortex influence at Lerwick, De Bilt and Uccle. Thus, which mechanism is dominant at a certain location will depend on meteorology and the relative position of the location to the forcing dynamics. This underlines the high spatial and temporal variability of the total ozone column. Severe low total ozone episodes seem to occur when the mentioned mechanisms are superimposed. 
Acknowledgements. Ozone sonde data were obtained from the NILU database and we like to thank the respective PIs Hennie Kelder (De Bilt), Hans Claude (Hohenpeissenberg), Peter Davis (Lerwick), Pierre Viatte, Rene Stubi and Bertrand Henchoz (Payerne, MeteoSwiss) as well as Anna Benesova and Pavla Skrivankova (Prague). We also like to thank G. Günther and P. Konopka for preparing the ECMWF files for the CLaMS simulations and A. Delcloo for plotting support. We thank the AURA-MLS team for providing the ozone data, and the MESSy-Team for providing the model system. The provision of access to the ECMWF meteorological analyses is gratefully acknowledged.

Edited by: M. Dameris

\section{References}

Allen, D. R. and Nakamura, N.: Dynamical reconstruction of the record low column ozone over Europe on 30 November, Geophys. Res. Lett., 29, 1362, doi:10.1029/2002GL014935, 2002.

Basher, R. E.: Review of the Dobson spectrophotometer and its accuracy, WMO Global ozone research and monitoring project, Report 13, WMO, Geneva, 1982.

Becker, G., Müller, R., McKenna, D. S., Rex, M., and Carslaw, K. S.: Ozone loss rates in the Arctic stratosphere in the winter 1991/92: Model calculations compared with match results, Geophys. Res. Lett., 25, 4325-4328, 1998.

Bian, H. and Prather, M. J.: Fast-J2: Accurate Simulation of Stratospheric Photolysis in Global Chemical Models, J. Atmos. Chem., 41, 281-296, 2002.

Biggs, R. H. and Joyner, M. E. B. (Eds.): Stratospheric Ozone Depletion/UV-B Radiation in the Biosphere, NATO ASI Ser. I 18, Kluwer Academic Publishers, Dordrecht, The Netherlands, 358 pp., 1994.

Buchholz, J.: Simulations of physics and chemistry of polar stratospheric clouds with a general circulation model, $\mathrm{Ph}$.D. thesis, Johannes Gutenberg University Mainz, Germany, 2005.

Dobson, G. M. B., Harrison, D. N., and Lawrence, L.: Measurements of the amount of ozone in the Earth's atmosphere and its relation to other geophysical conditions, Proc. R. Soc. Lon. Ser.A., 110, 660-693, 1929.

Fioletov, V. E., Kerr, J. B., McElroy, C. T., Wardle, D. I., Savastiouk, V., and Grajnar, T. S.: The Brewer reference triad, Geophys. Res. Lett., 32, L20805, doi:10.1029/2005GL024244, 2005.

Gidel, L. T., Crutzen, J., and Fishman, J.: A two-dimensional photochemical model of the atmosphere: 1. Chlorocarbon emissions and their effect on stratospheric ozone, J. Geophys. Res., 88, 6622-6640, 1983.

Grooß, J.-U.: Modelling of Stratospheric Chemistry Based on HALOE/UARS Satellite Data, Ph.D. thesis, University of Mainz, Germany, 1996.

Grooß, J.-U. and Müller, R.: Simulation of ozone loss in Arctic winter 2004/2005, Geophys. Res. Lett., 34, L05804, doi:10.1029/2006GL028901, 2007.

Hanson, D. and Mauersberger, K.: Laboratory studies of the nitric acid trihydrate: Implications for the south polar stratosphere, Geophys. Res. Lett., 15, 855-858, 1988.

Harris, N. R. P., Rex, M., Goutail, F., Knudsen, B. M., Manney, G. L., Müller, R., and von der Gathen, P.: Comparison of empirically derived ozone losses in the Arctic vortex , J. Geophys. Res., 107(D20), 8264, doi:10.1029/2001JD000482, 2002.

Hilsenrath, E., Attmannspacher, W., Bass, A., Evans, W., Hagemeyer, R., Barnes, R. A., Komhyr, W., Mauersberger, K., Mentall, J., Profitt, M., Robbins, D., Taylor, S., Torres, A., and Weinstock, E.: Results from the Balloon Ozone Intercomparison Campaign (BOIC), J. Geophys. Res., 91, 13137-13152, 1986.

Holton, J. R.: An Introduction to Dynamic Meteorology, Elsevier Academic Press, 535 pp., 2004.

Hood, L. L. and Soukharev, B. E.: Interannual variations of total ozone at northern midlatitudes correlated with stratospheric EP fluxes and potential vorticity, J. Atmos. Sci., 62, 3724-3740, 2005.

Hood, L. L., Soukharev, B., Fromm, M., and McCormack, J.: Origin of extreme ozone minima at middle to high northern latitudes, J. Geophys. Res., 106, 20925-20940, 2001.

James, P. M.: A climatology of ozone mini-holes over the Northern Hemisphere, Int. J. Climatol., 18, 1287-1303, 1998.

James, P. M. and Peters, D.: The Lagrangian structure of ozone mini-holes and potential vorticity anomalies in the Northern Hemisphere, Ann. Geophys., 20, 835-846, 2002, http://www.ann-geophys.net/20/835/2002/.

James, P. M., Peters, D., and Waugh, D. W.: Very low ozone episodes due to polar vortex displacement, Tellus B, 52B, 11231137, 2000.

Jöckel, P., Sander, R., Kerkweg, A., and Lelieveld, J.: Technical note: The Modular Earth Submodel System (MESSy) - a new approach towards Earth System Modeling, Atmos. Chem. Phys., 5, 433-444, 2005, http://www.atmos-chemphys.net/5/433/2005/.

Jöckel, P., Tost, H., Pozzer, A., Brühl, C., Buchholz, J., Ganzeveld, L., Hoor, P., Kerkweg, A., Lawrence, M., Sander, R., Steil, B., Stiller, G., Tanarhte, M., Taraborrelli, D., van Aardenne, J., and Lelieveld, J.: The atmospheric chemistry general circulation model ECHAM5/MESSy1: consistent simulation of ozone from the surface to the mesosphere, Atmos. Chem. Phys., 6, 50675104, 2006, http://www.atmos-chem-phys.net/6/5067/2006/.

Keckhut, P., David, C., Marchand, M., Bekki, S., Jumelet, J., Hauchecorne, A., and Höpfner, M.: Observation of polar stratospheric clouds down to the Mediterranean coast, Atmos. Chem. Phys., 7, 5275-5281, 2007, http://www.atmos-chem-phys.net/7/5275/2007/.

Keil, M., Jackson, D. R., and Hort, M. C.: The January 2006 low ozone event over the UK, Atmos. Chem. Phys., 7, 961-972, 2007, http://www.atmos-chem-phys.net/7/961/2007/.

Kerkweg, A., Sander, R., Tost, H., and Jöckel, P.: Technical note: Implementation of prescribed (OFFLEM), calculated (ONLEM), and pseudo-emissions (TNUDGE) of chemical species in the Modular Earth Submodel System (MESSy), Atmos. Chem. Phys., 6, 3603-3609, 2006, http://www.atmos-chem-phys.net/6/3603/2006/.

Khosrawi, F., Müller, R., Profitt, M. H., Ruhnke, R., Kirner, O., Jckel, P., Grooß, J.-U., Urban, J., Murtagh, D., and Nakajima, H.: Evaluation of CLaMS, KASIMA and ECHAM/MESSy1 simulations in the lower stratosphere using observations of Odin/SMR and ILAS/ILAS-II, Atmos. Chem. Phys., 9, 5759-5783, 2009, http://www.atmos-chem-phys.net/9/5759/2009/.

Koch, G., Wernli, H., Schwierz, C., Staehelin, J., and Peter, T.: A composite study on the structure and formation of ozone mini- 
holes and minihighs over central Europe, Geophys. Res. Lett., 32, L12810, doi:10.1029/2004GL022062, 2005.

Komhyr, W. D., Barnes, R. A., Brothers, G. B., Lathrop, J. A., and Opperman, D. P.: Electrochemical Concentration Cell ozonesonde performance evaluation during STOIC 1989, J. Geophys. Res., 100, 9231-9244, 1995.

Konopka, P., Steinhorst, H.-M., Grooß, J.-U., Günther, G., Müller, R., Elkins, J. W., Jost, H.-J., Richard, E., Schmidt, U., Toon, G., and McKenna, D. S.: Mixing and ozone loss in the 1999-2000 Arctic vortex: Simulations with the three-dimensional Chemical Lagrangian Model of the Stratosphere CLaMS, J. Geophys. Res., 109, D02315, doi:10.1029/2003JD003792, 2004.

Konopka, P., Spang, R., Günther, G., Müller, R., McKenna, D. S., Offermann, D., and Riese, M.: How homogeneous and isentropic is stratospheric mixing? Comparison of CRISTA1 observations with transport studies based on the Chemical Lagrangian Model of the Stratosphere CLaMS, Q. J. Roy. Meteor. Soc., 131(606B), 565-579, 2005.

Kouker, W., Langbein, I., Reddmann, T., and Ruhnke, R.: The Karlsruhe Simulation Model of the Middle Atmosphere (KASIMA), Version 2, FZK Report 6278, 1999.

Lemoine, R. and De Backer, H.: Assessment of the Uccle ozone sounding time series quality using SAGE II data, J. Geophys. Res., 106(D13), 14515-14523, 2001.

McKenna, D. S., Jones, R. L., Austin, J., Browell, E. V., McCormick, M. P., Krüger, A. J., and Tuck, A. F.: Diagnostic studies of the Antarctic vortex during the 1987 airborne Antarctic ozone experiment: Ozone miniholes, J. Geophys. Res., 94 11641-11668, 1989.

McKenna, D. S., Grooß, J.-U., Günther, G., Konopka, P., Müller, R., Carver, G., and Sasano, Y.: A new Chemical Lagrangian Model of the Stratosphere: 2. Formulation of chemistry scheme and initialization, J. Geophys. Res., 107(D15), 4256, doi:10.1029/2000JD000113, 2002a.

McKenna, D. S., Konopka, P., Grooß, J.-U., Günther, G., Müller, R., Spang, R., Offermann, D., and Orsolini, Y.: A new Chemical Lagrangian Model of the Stratosphere: 1. Formulation of advection and mixing, J. Geophys. Res., 107(D16), 4309, doi:10.1029/2000JD000114, 2002b.

Newman, P. A., Lait, L. A., and Schoeberl, M. R.: The morphology and meteorology of Southern Hemisphere spring total ozone mini-holes, Geophys. Res. Lett., 15, 923-926, 1988.

Orsolini, Y. and Limpasuvan, V.: The North Atlantic Oscillation and the occurrence of ozone miniholes, Geophys. Res. Lett., 28, 4099-4102, 2001.

Orsolini, Y. and Nikulin, G.: A low ozone episode during the European heatwave of August 2003, Q. J. Roy. Meteorol. Soc., 132, 667-680, 2006.

Orsolini, Y., Cariolle, D., and Déqué, M.: Ridge formation in the lower stratosphere and its influence on ozone transport: a general circulation model study during late January 1992, J. Geophys. Res., 100, 11113-11135, 1995.

Peters, D., Egger, J., and Entzian, G.: Dynamical aspects of ozone mini-hole formation, Meteorol. Atmos. Phys., 55, 205-214, 1995.

Petzoldt, K.: The role of dynamics in total ozone deviations from their long-term mean over the Northern Hemisphere, Ann. Geophys., 17, 231-241, 1999, http://www.ann-geophys.net/17/231/1999/.

Reddmann, T., Ruhnke, R., and Kouker, W.: Three-dimensional model simulations of $\mathrm{SF}_{6}$ with mesospheric chemistry, J. Geophys. Res., 106, 14525-14537, 2001.

Reed, R. J.: The role of vertical motions in ozone-weather relationship, J. Meteorol., 7, 263-267, 1950.

Reid, S. J., Tuck, A. F., and Kildaris, G.: On the changing abundance of ozone minima at Northern midlatitudes, J. Geophys. Res., 105, 12169-12180, 2000.

Röckner, E., Brokopf, R., Esch, M., Giorgetta, M., Hagemann, S., Kornblueh, L., Manzini, E., Schlese, U., and Schulzweida, U.: Sensitivity of simulated climate to horizontal and vertical resolution in the ECHAM5 atmosphere model, J. Climate, 19, 37713791, 2006.

Ruhnke, R., Kouker, W., and Reddmann, T.: The influence of the $\mathrm{OH}+\mathrm{NO}_{2}+\mathrm{M}$ reaction on the $\mathrm{NO}_{\mathrm{y}}$ partitioning in the late arctic winter 1992/1993 as studied with KASIMA, J. Geophys. Res., 104, 3755-3772, 1999.

Sander, R., Kerkweg, A., Jöckel, P., and Lelieveld, J.: Technical note: The new comprehensive atmospheric chemistry module MECCA, Atmos. Chem. Phys., 5, 445-450, 2005,

http://www.atmos-chem-phys.net/5/445/2005/.

Semane, N., Bencherif, H., Morel, B., Hauchecorne, A., and Diab, R. D.: An unusual stratospheric ozone decrease in the Southern Hemisphere subtropics linked to isentropic air-mass transport as observed over Irene $\left(25.5^{\circ} \mathrm{S}, 28.1^{\circ} \mathrm{E}\right)$ in mid-May 2002, Atmos. Chem. Phys., 6, 1927-1936, 2006, http://www.atmos-chem-phys.net/6/1927/2006/.

Smit, H. G. J., Straeter, W., Johnson, B. J., Oltmans, S. J., Davies, J., Tarasick, D. W., Hoegger, B., Stubi, R., Schmidlin, F. J., Northam, T., Thompson, A. M., Witte, J. C., Boyd, I., and Posny, F.: Assessment of the performance of ECC-ozonesondes under quasi-flight conditions in the environmental simulation chamber: Insights from the Juelich Ozone Sonde Intercomparison Experiment (JOSIE), J. Geophys. Res., 112, D19306, doi:10.1029/2006JD007308, 2007.

Solomon, S.: Stratospheric ozone depletion: A review of concepts and history, Rev. Geophys., 37, 275-316, 1999.

Stick, C., Krüger, K., Schade, N. H., Sandmann, H., and Macke, A.: Episode of unusually high solar ultraviolet radiation over central Europe due to dynamical reduced total ozone in May 2005, Atmos. Chem. Phys., 6, 1771-1776, 2006,

http://www.atmos-chem-phys.net/6/1771/2006/.

Teitelbaum, H., Moustaoui, M., and Fromm, M.: Exploring polar stratospheric cloud and ozone minihole formation: The primary importance of synoptic-scale flow perturbations, J. Geophys. Res., 106, 28173-28188, 2001.

Tilmes, S., Müller, R., Engel, A., Rex, M., and Russell III, J. M.: Chemical ozone loss in the Arctic and Antarctic stratosphere between 1992 and 2005, Geophys. Res. Lett., 33, L20812, doi:10.1029/2006GL026925, 2006.

Tost, H., Jöckel, P., Kerkweg, A., Pozzer, A., Sander, R., and Lelieveld, J.: Global cloud and precipitation chemistry and wet deposition: tropospheric model simulation with ECHAM5/MESSy1, Atmos. Chem. Phys., 7, 2733-2757, 2007a, http://www.atmos-chem-phys.net/7/2733/2007/.

Tost, H., Jöckel, P., and Lelieveld, J.: Lightning and convection parameterisations - uncertainties in global modelling, Atmos. Chem. Phys., 7, 4553-4568, 2007b, 
http://www.atmos-chem-phys.net/7/4553/2007/.

WHO: Global solar UV index: a pratical guide. A joint recommendation of the World Health Organisation, World Meteorological Organisation, United Nations Environment Programme, and the International Commission on Non-Ionizing Radiation Protection, WHO, Geneva, 2002.
WMO: Scientific assessment of ozone depletion: 2002, global ozone research and monitoring project, Report No. 47, 498 pp., Geneva, 2003.

WMO: Joint WMO/EC SCOUT-O3 Arctic ozone bulletin, Arctic ozone bulletin No 1/2006, Winter/Spring Summary, 15 September 2006, 2006. 